\title{
Elemental and Thermochemical Analyses of Materials after Electrical Discharge Machining in Water: Focus on Ni and Zn
}

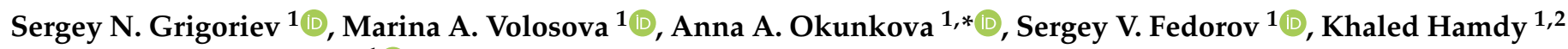 \\ and Pavel A. Podrabinnik ${ }^{1}$ (D) \\ 1 Department of High-Efficiency Processing Technologies, Moscow State University of Technology STANKIN, \\ Vadkovsky per. 1, 127055 Moscow, Russia; prof.s.n.grigoriev@gmail.com (S.N.G.); \\ m.volosova@stankin.ru (M.A.V.); sv.fedorov@icloud.com (S.V.F.); eng_khaled2222@mu.edu.eg (K.H.); \\ p.podrabinnik@stankin.ru (P.A.P.) \\ 2 Production Engineering and Mechanical Design Department, Faculty of Engineering, Minia University, \\ Minia 61519, Egypt \\ * Correspondence: a.okunkova@stankin.ru; Tel.: +7-909-913-1207
}

\section{check for} updates

Citation: Grigoriev, S.N.; Volosova, M.A.; Okunkova, A.A.; Fedorov, S.V.; Hamdy, K.; Podrabinnik, P.A. Elemental and Thermochemical Analyses of Materials after Electrical Discharge Machining in Water: Focus on $\mathrm{Ni}$ and Zn. Materials 2021, 14, 3189. https:// doi.org/10.3390/ma14123189

Academic Editors: Carla Martini and Ramona Sola

Received: 6 May 2021

Accepted: 7 June 2021

Published: 9 June 2021

Publisher's Note: MDPI stays neutral with regard to jurisdictional claims in published maps and institutional affiliations.

Copyright: (c) 2021 by the authors. Licensee MDPI, Basel, Switzerland. This article is an open access article distributed under the terms and conditions of the Creative Commons Attribution (CC BY) license (https:/ / creativecommons.org/licenses/by/ $4.0 /)$.

\begin{abstract}
The mechanism of the material destruction under discharge pulses and material removal mechanism based on the thermochemical nature of the electrical erosion during electrical discharge machining of conductive materials were researched. The experiments were conducted for two structural materials used in the aerospace industry, namely austenite anticorrosion X10CrNiTi18-10 (12kH18N10T) steel and 2024 (D16) duralumin, machined by a brass tool of $0.25 \mathrm{~mm}$ in diameter in a deionized water medium. The optimized wire electrical discharge machining factors, measured discharge gaps (recommended offset is 170-175 $\mu \mathrm{m}$ and 195-199 $\mu \mathrm{m}$, respectively), X-ray photoelectron spectroscopy for both types of materials are reported. Elemental analysis showed the presence of metallic $\mathrm{Zn}, \mathrm{CuO}$, iron oxides, chromium oxides, and $58.07 \%$ carbides (precipitation and normal atmospheric contamination) for steel and the presence of metallic $\mathrm{Zn}, \mathrm{CuO}, \mathrm{ZnO}$, aluminum oxide, and $40.37 \%$ carbides (contamination) for duralumin. For the first time, calculating the thermochemistry parameters for reactions of $\mathrm{Zn}(\mathrm{OH})_{2}, \mathrm{ZnO}$, and $\mathrm{NiO}$ formation was produced. The ability of $\mathrm{Ni}$ of chrome-nickel steel to interact with $\mathrm{Zn}$ of brass electrode was thermochemically proved. The standard enthalpy of the $\mathrm{Ni}_{5} \mathrm{Zn}_{21}$ intermetallic compound formation (erosion dust) $\Delta H^{0}{ }_{298}$ is $-225.96 \mathrm{~kJ} / \mathrm{mol}$; the entropy of the crystalline phase $S^{c}{ }_{\text {int }}$ is $424.64 \mathrm{~J} /(\mathrm{mol} \cdot \mathrm{K})$.
\end{abstract}

Keywords: electrical erosion; enthalpy; entropy; $\mathrm{Ni}_{5} \mathrm{Zn}_{21}$; removal mechanism; submicrostructure; thermochemistry

\section{Introduction}

Electrical discharge machining is a type of machining that consists of changing the geometric parameters, surface quality, and physical properties of the surface of a conductive workpiece under the influence of electric discharges between the workpiece and the tool electrode [1-4]. Despite the well-known effect of electrical discharges on the surface being machined, the nature of the processes between two electrodes remains unknown.

It should be noted that electrical discharge machining is different from electrochemical machining since the technologies differ in principles. Electrochemical machining is a method for machining electrically conductive materials by the anodic dissolution of the material in an electrolyte under an electric current. The method was proposed in 1911 by the famous Russian chemist E.I. Shpitalsky and modified by V.N. Gusev (W. Gussef), who first proposed conducting machining on the narrow interelectrode gaps (up to tenths of a millimeter) with forced electrolyte pumping [5,6]. The electrochemical discharge machining process is a hybrid machining process having advantages of electrochemical machining and electrical discharge machining and is suitable for nonconductive materials, where electric discharge takes place through the electrolyte and plays a critical role [7]. 
Unlike these two technologies, electrical discharge machining allows changing the sizes and shapes of electrically conductive materials with high accuracy $( \pm 1-2 \mu \mathrm{m})$ in a chemically neutral medium of a liquid dielectric (deionized water, hydrocarbons) [8,9]. First developed and patented in 1986 [10], electrical discharge machining techniques can cause electrical destruction of nonconductive materials. However, the developed techniques demonstrate very low efficiency. The maximum achieved depth of the machined holes in a non-oil medium for aluminum-based ceramics $\left(\mathrm{Al}_{2} \mathrm{O}_{3}, \mathrm{AlN}\right)$ does not exceed $700 \mu \mathrm{m}$ [11] (machining was conducted for a few hours with $\mathrm{Ag}$ nanoparticle suspension). The results for $\mathrm{Si}_{3} \mathrm{~N}_{4}$ have never been reproduced [12]. $\mathrm{ZrO}_{2}$ is easily subjected to electrical discharge machining up to the depth of 5000-8000 $\mu \mathrm{m}$ in an oil medium [13]. However, no one can explain why this technique never worked so efficiently with aluminum-based ceramics or dielectrics. The spectrum of techniques includes modification of workpiece conductivity using the following conductive agents:

- Conductive nanoparticles introduced into nonconductive matrix [14,15], which have been known since the beginning of the 1980s;

- Conductive nano- and microparticles introduced into the discharge gap [11,12,16-19], which were first proposed at the beginning of the 1980s (some of the authors even proposed modifying the interelectrode gap conditions by the introduction of nonconductive particles during machining of conductive materials [20]);

- Conductive adherent coating of nonconductive workpiece surfaces (auxiliary electrode) $[13,14]$.

In all the proposed techniques, the problem of pulse reinitiation after the completed sublimation of additives from the discharge gap remains.

One way to solve this global problem of efficiency is to research the nature of the erosion process of conductive materials to understand better how the erosion process can be better designed using the chemical properties of chosen electrodes and working medium.

For many years, researchers have declared that the erosion process has thermal nature [21,22] or even mixed thermal and mechanical nature [23] when the physical contact between electrodes is absent, in contrast to the mechanical nature of destruction during milling, turning, and punching operations (physical wear of the tool [24-27]).

Indeed, the nature of erosional destruction is of a mixed nature, but not thermomechanical; it is thermochemical. Since electrical discharge machining, electrochemical machining, and electrochemical discharge machining are contactless machining methods, there is always an interelectrode gap between the tool and workpiece electrodes, and the physical contact is absent. This allows machining materials despite their hardness or ductility with high precision $[5-7,28]$.

The absence of mechanical nature is proved by observation of the even formed surfaces $[1-4,18,21,22]$ and various works devoted to the research of acoustic oscillations in the full range of spectra [1,29]. Results of research considering erosion products have shown the absence of mechanical contact between electrodes $[30,31]$ and wire oscillations with an amplitude of about $\pm|9+i| \mathrm{nm}$ (complex number) for steel workpieces and brass wire in water medium excited by working and idle pulses. Thus, the erosion process cannot have any thermomechanical nature since there is no mechanics.

Thermochemical nature is the novelty of this research, proved by X-ray spectroscopy and thermochemical equations of a thermally isolated system (Gibbs energy, entropy, and enthalpy of formation, equilibrium temperature).

The founders of the method, Prof. B.R. Lazarenko and Prof. N.I. Lazarenko [28], declared the thermochemical nature of the phenomena. Since then, it has been raised only once for the combined method of mechanical milling assisted by electric discharge [32] and repeated for electrical discharge machining of dielectric ceramics [33]. A. Calka [32] reported detected erosion products such as amorphous phases, nanocrystalline and quasicrystalline materials, supersaturated solid solutions, reduced minerals, high-surface-area catalysts, and reactive chemicals. The powder initiated solid-solid, solid-liquid, and solidgas reactions, and a separate materials synthesis and the reaction of workpiece material in a 
gas atmosphere under discharge pulses were shown. Y. Guo [33] reported on the evidence of the chemical reactions occurring during high-speed wire electrical discharge machining insulating zirconia using assisting electrode technique. Up to now, there have been no other works devoted to the analysis of thermochemical parameters between electrodes in the presence of heat and reactions with the formation of intermetallics.

For the first time, the Lazarenko spouses, who developed the electrical discharge machining method in 1942, mentioned the electrical and chemical nature of the method. Since then, it has been mentioned by only A. Calka and Y. Guo in their articles on chemical transformations occurring on machined surfaces. A. Calka plunged into this issue in sufficient detail from the material science point of view (eutectic, crystalline formation) but only touched on the topic of electrical discharge machining, whileY. Guo casually mentioned the thermochemical nature in the context of the machining of insulating ceramics. None of the authors who have investigated electrical erosion have gone so far as to explain the resulting modifications of the workpiece layers from a thermochemical point of view. There is no explanation of why the assisting alumina powder does not allow intensifying the machining of steel, why sparks and a cloud of black sediment are formed during electrical discharge machining of stainless steel, or why insulating zirconium dioxide can be machined in the hydrocarbon medium using the assistant electrode technique when aluminum oxide and nitride are very laborious to process.

This article presents a new, unique approach to understanding the deep nature of electrical erosion after the discharge channel has formed. It makes it possible to evaluate the erosion products; select them based on the properties of the electrical conductivity of the erosion products; and calculate theoretically the probability of the formation of certain erosion products based on the calculated Gibbs energy, entropy and enthalpy of formation, and equilibrium temperature.

Further understanding of the electrical discharge machining process is no longer possible without a thermochemical analysis of the interaction of the components of the electrodes and the dielectric medium. It will improve the efficiency of electrical discharge machining of conductive and nonconductive materials, give an exhaustive explanation of the observed phenomenon in the discharge channel, avoid combinations of the electrode and working medium materials that reduce the efficiency of electrical discharge machining, and predict the chemical content of the erosion products that assist or hamper machining.

This study is devoted to researching thermochemical interactions (phenomena) between tool electrode, workpiece, and dielectric medium components during wire electrical discharge machining; calculation of thermochemical parameters of erosion products' formation; and substantiation of chemical reactions by thermochemical approach.

Research on the nature of electrical erosion wear was conducted for two types of structural materials, namely nickel-containing and non-nickel-containing materials, machined with a brass tool electrode in deionized water using spectroscopy and analytical research of the chemical interaction of electrodes and working medium components based on thermochemical parameters such as enthalpy, entropy, Gibbs energy, and equilibrium temperatures. Calculations are provided for the formation of conductive or nonconductive erosion products: $\mathrm{Zn}(\mathrm{OH})_{2}, \mathrm{ZnO}, \mathrm{NiO}, \mathrm{Ni}_{5} \mathrm{Zn}_{21}$.

The scientific novelty of the work is in the following:

- The new data on thermochemical phenomena that occurred between electrodes and deionized water medium in the presence of plasma heat $\left(10,000{ }^{\circ} \mathrm{C}\right)$;

- Completed thermochemical analyses of chemical interactions at the surface and nearsurface layers after electrical discharge machining.

The practical significance of the work is the development of the theoretical method of thermochemical prediction of erosion product chemical content to evaluate the electrical conditions in the discharge gap suitable for conductive and nonconductive materials.

The tasks of the study are the research of the surface topology of two structural materials, namely austenite anticorrosion X10CrNiTi18-10 (12kH18N10T) steel (nickel-contacting) and 2024 (D16) duralumin (non-nickel-containing), after electrical discharge machining 
with a brass wire tool electrode in a deionized water medium and the thermochemical analysis of chemical reactions between electrodes and working fluid (Figure 1).

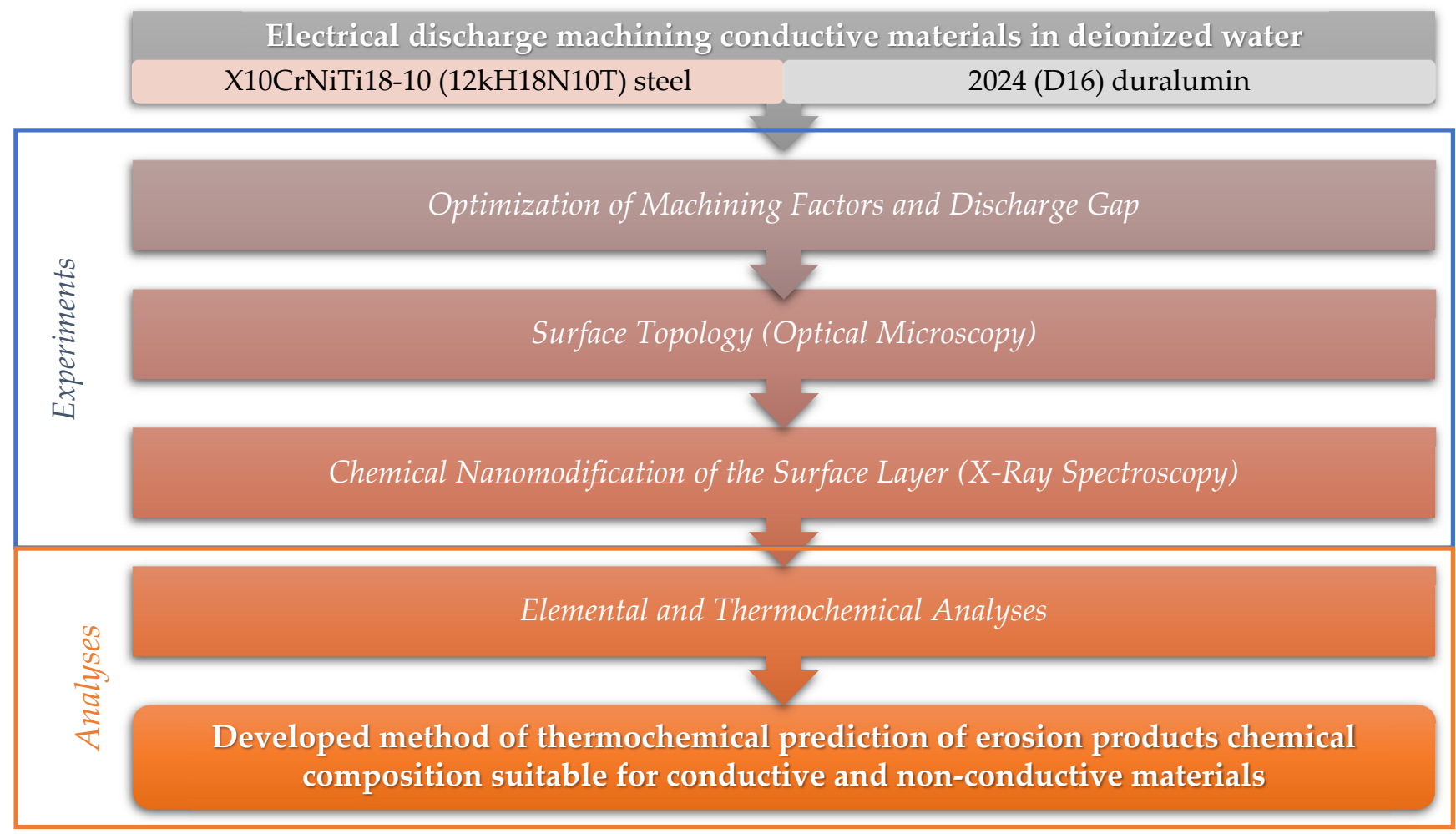

Figure 1. Flow chart of the stepwise procedure of experiments and analyses carried out.

\section{Materials and Methods}

\subsection{Equipment and Machining Factors}

A four-axis computer numerical control (CNC) machine Seibu M500S (Seibu Electric \& Machinery Co., Ltd., Fukuoka, Japan) (Table 1) was used in the experiments for wire electrical machining in deionized water.

Table 1. Main characteristics of a Seibu M500S wire electrical discharge machine.

\begin{tabular}{cc}
\hline Characteristic, Measuring Unit & Value \\
\hline Max motions in working area $\mathrm{X} \times \mathrm{Y} \times \mathrm{Z}, \mathrm{mm}$ & $500 \times 350 \times 310$ \\
Max conical machining angle, degrees & \pm 10 \\
Max weight of workpiece, $\mathrm{kg}$ & 800 \\
Axes positioning accuracy, $\mu \mathrm{m}$ & $\pm 1-2$ \\
Achievable roughness parameter $R_{a}, \mu \mathrm{m}$ & 0.4 \\
Dielectric medium & Deionized water \\
Machine body & Solid, grey cast iron \\
Max power consumption, $\mathrm{kW}$ & not confined \\
\hline
\end{tabular}

Workpieces were immersed in a working medium for $10 \mathrm{~min}$ before machining to avoid dimensional fluctuations of the temperature difference between the environment and the working medium (deionized water). The level of the medium was established at 1-2 $\mathrm{mm}$ above workpiece height. The upper wire guide was $2-5 \mathrm{~mm}$ above the dielectric medium [34,35]. The wire tool electrode was made of brass (Cu-65\%; Zn-35\%) Novotec Ultra-Brass wire (Germany) with a diameter $d_{w}$ of $0.25 \mathrm{~mm}$ and a tensile strength of $900 \mathrm{~N} / \mathrm{mm}^{2}$. The CNC programs were prepared manually; experiment factors were chosen following recommendations of [36-38] and are presented in Table 2. The tool electrode had a negative bias, and a workpiece was positive. Flushing was used during experiments to 
provide better performance and machining stability [39]. The path offset was not taken into account during machining $[1,37]$.

Table 2. Electrical discharge machining factors (Seibu M500S machine).

\begin{tabular}{cc}
\hline Factors & Values $^{\mathbf{1}}$ \\
\hline Operational voltage $\left(V_{o}\right)$ & $55,60,65$ \\
Auxiliary voltage $\left(V_{g}\right)$ & 32 \\
Operational current strength $(I)$ & 8 \\
Auxiliary current (reverse circuit) $\left(I_{a}\right)$ & 43 \\
Discharge time to time off ratio $\left(T_{o f f}\right)$ & 6 \\
Time intermittent pause $\left(T_{i}\right)$ & 305 \\
Feed rate $\left(R_{f}\right)$ & Adaptive \\
Wire tool rewinding speed $\left(R_{r}\right)$ & 35 \\
Wire tool tension $\left(W_{t}\right)$ & $30,35,40$ \\
Dielectric pressure in nozzles $\left(F_{d}\right)$ & 245 \\
\hline
\end{tabular}

${ }^{1}$ Provided in equivalent units of the machine.

\subsection{Materials to Be Machined}

Two structural materials typical for the aerospace industry and tool production were chosen for the experiments, namely anticorrosion chrome-nickel X10CrNiTi18-10 (12kH18N10T) steel of austenite class (Table 3) and 2024 duralumin (D16, Table 4). The thickness of the samples was $18-20 \mathrm{~mm}$. It should be noted that chromium content provides anticorrosion properties of the steel when nickel is responsible for its austenite class that improves its machinability and extends the exploitation properties. The titanium addition hampers chromium carbides' formation and forms refractory carbides of titanium in reaction with carbon. This type of chromium-nickel steel dominates the modern rolled metal market [40-43]. Duralumin is used mainly in a quenched state and is classified as a durable thermohardened construction material for the aerospace industry and unsuitable for welding [44,45].

Table 3. Chemical content of X10CrNiTi18-10 (12kH18N10T) steel.

\begin{tabular}{lcccccccccc}
\hline Element & Fe & Cr & Ni & Ti & Si & S & Mn & Cu & P & C \\
\hline wt. $\%$ & Balance & $17-19$ & $9-11$ & $\sim 0.8$ & $<0.8$ & $<0.02$ & $<2.0$ & $<0.03$ & $<0.035$ & $\sim 0.12$ \\
\hline
\end{tabular}

Table 4. Chemical content of 2024 (D16) duralumin.

\begin{tabular}{cccccccccc}
\hline Element & Al & $\mathbf{C u}$ & $\mathbf{M g}$ & $\mathbf{M n}$ & $\mathbf{F e}$ & $\mathrm{Si}$ & $\mathrm{Zn}$ & $\mathbf{N i}$ & $\mathrm{Ti}$ \\
\hline wt. $\%$ & $90.8-94.7$ & $3.8-4.9$ & $1.2-1.8$ & $0.3-0.9$ & $<0.5$ & $<0.5$ & $<0.3$ & $<0.1$ & $<0.1$ \\
\hline
\end{tabular}

The specific electrical resistance $\rho$ of the workpieces and wire tool electrode was controlled using a Fischer Sigmascope SMP10 device (Helmut Fischer GmbH, Sindelfingen, Germany) (Table 5) that measures the percentage of the control sample's electrical conductance made of annealed bronze in the range of $1-112 \%$. The measured values were converted to $\frac{\Omega \cdot \mathrm{mm}^{2}}{\mathrm{~m}}$. The linear thermal expansion coefficient; thermal conductivity; and melting, boiling, and decomposition points are presented in Table 5 [46-51]. 
Table 5. Electrical and thermal properties of some materials at $+20^{\circ} \mathrm{C}$.

\begin{tabular}{|c|c|c|c|}
\hline Materials & $\begin{array}{c}\text { Specific Electrical Resistance } \\
\qquad \rho\left[\frac{\Omega \cdot \mathrm{mm}^{2}}{\mathrm{~m}}\right]\end{array}$ & Melting Point $T_{m}\left[{ }^{\circ} \mathrm{C}\right]$ & Decomposition Point $T_{d}\left[{ }^{\circ} \mathrm{C}\right]$ \\
\hline $\begin{array}{c}\text { X10CrNiTi18-10 } \\
\text { (12kH18N10T) steel }\end{array}$ & 0.725 & $1420-1800$ & - \\
\hline 2024 (D16) duralumin & 0.052 & 650 & - \\
\hline CuZn35 brass alloy (annealed) & 0.065 & 920 & - \\
\hline Nickel ${ }^{1}$ & 0.087 & $1453-1455$ & 2732-2913 (boiling) \\
\hline Zinc $^{1}$ & 0.059 & 419.6 & 906.2 (boiling) \\
\hline $\mathrm{NiO}^{1}$ & - & 1682-1955 & 1230 (sublimation) \\
\hline $\mathrm{ZnO}^{1}$ & $\sim 0.01 \times 10^{14}$ & 1975 (decomposition) & 1800 (sublimation) \\
\hline
\end{tabular}

${ }^{1}$ Given for references.

\subsection{Characterization of the Samples}

The discharge gap and topology were controlled optically using an Olympus BX51M instrument (Ryf AG, Grenchen, Switzerland).

The cross-sections were prepared using Opal 410, Jade 700, and Saphir 300 sample equipment (ATM, Haan, the Netherlands) and standard techniques. An epoxy resin with quartz sand was used as a filler.

Elemental analyses of the machined surfaces were conducted using Thermo Scientific's K-ALPHA X-ray photoelectron spectrometer (Thermo Fisher Scientific Inc., Bremen, Germany) equipped with an Avantage Data System (version 5.0, Thermo Fisher Scientific Inc., Bremen, Germany).

\subsection{Thermochemical Analyses}

To assess the chemical composition of erosion products, namely the probability of specific chemical reactions in the presence of heat, the authors proposed an estimation technique based on the main thermochemical parameters, namely the enthalpy and entropy of formation, the Gibbs energy, and the equilibrium temperature of the proposed systems [52]:

$$
\Delta G_{T}^{0}=\Delta H_{298}^{0}-T \cdot \Delta S_{298}^{0}\left[\frac{\mathrm{kJ}}{\mathrm{mol}}\right] .
$$

It is proposed to focus on the interaction of oxygen with the components of the material of the workpiece and tool electrodes since the electrical discharge machining is carried out in deionized water. Attention is also be paid to the tool electrode components' behavior and the interaction of the nickel of the anticorrosion steel with the zinc of the tool electrode. For comparison purposes, the other aluminum alloy billet contained no nickel.

The chemical reactions with $\mathrm{Zn}$ of brass wire tool electrode and Ni of chrome-nickel steel with water medium can be presented as follows $[14,53,54]$ when $\mathrm{NiO}$ is taken as the most likely compound of nickel with oxygen:

$$
\begin{gathered}
\mathrm{Zn}^{2+}+2 \mathrm{H}_{2} \mathrm{O} \rightarrow \mathrm{Zn}(\mathrm{OH})_{2}+\mathrm{H}_{2} \uparrow, \\
\mathrm{Zn}^{2+}+\mathrm{H}_{2} \mathrm{O} \rightarrow \mathrm{ZnO}+\mathrm{H}_{2} \uparrow, \\
\mathrm{Ni}^{2+}+\mathrm{H}_{2} \mathrm{O} \rightarrow \mathrm{NiO}+\mathrm{H}_{2} \uparrow .
\end{gathered}
$$

Knowing the peculiarity of nickel to form intermetallic compounds with some metals, we will consider the possibility of forming a $\mathrm{Ni}_{5} \mathrm{Zn}_{21}$ intermetallic compound ( $\gamma$-phase, evidenced by the constancy of the entropy factor) [55] as a more prevalent chemical reaction (reverse corrosion process):

$$
\begin{gathered}
\mathrm{Ni}^{2+}+\mathrm{Zn}^{2+} \stackrel{+\mathrm{Zn}^{2+}}{\rightarrow} \mathrm{NiZn} \stackrel{+\mathrm{Zn}^{2+}}{\rightarrow} \mathrm{NiZn}_{3} \stackrel{+\mathrm{Zn}^{2+}}{\rightarrow} \mathrm{Ni}_{5} \mathrm{Zn}_{21} \text { (metastable phase) } \stackrel{\mathrm{Zn}^{2+}}{\rightarrow} \mathrm{Ni}_{5} \mathrm{Zn}_{21} \\
5 \mathrm{Ni}^{2+}+21 \mathrm{Zn}^{2+} \rightarrow \mathrm{Ni}_{5} \mathrm{Zn}_{21} .
\end{gathered}
$$


A feature of this study is that, although the main thermochemical parameters for the theoretical assessment of reactions can be found in the reference literature, calculating these parameters for an intermetallic compound is an urgent scientific and technical problem.

\section{Results}

\subsection{Optimization of Machining Factors and Discharge Gap}

The electrical discharge machining was conducted based on standard recommendations similarly applicable to both types of materials. The experiments showed that the stabilizing was achieved at 60 and $55 \mathrm{~V}$ for operational bias $V_{0}$ and 35 and $40 \mathrm{~N}$ for wire tension $W_{t}$ during machining of X10CrNiTi18-10 (12kH18N10T) steel and 2024 (D16) duralumin, respectively. The minimum optically measured discharge gap value $\Delta$ corresponds to stable machining mode for both materials (Figure 2). Verification of machining factors provided their optimized values in measuring units of open CNC systems.

X10CrNiTi18-10 (12kH18N10T) steel

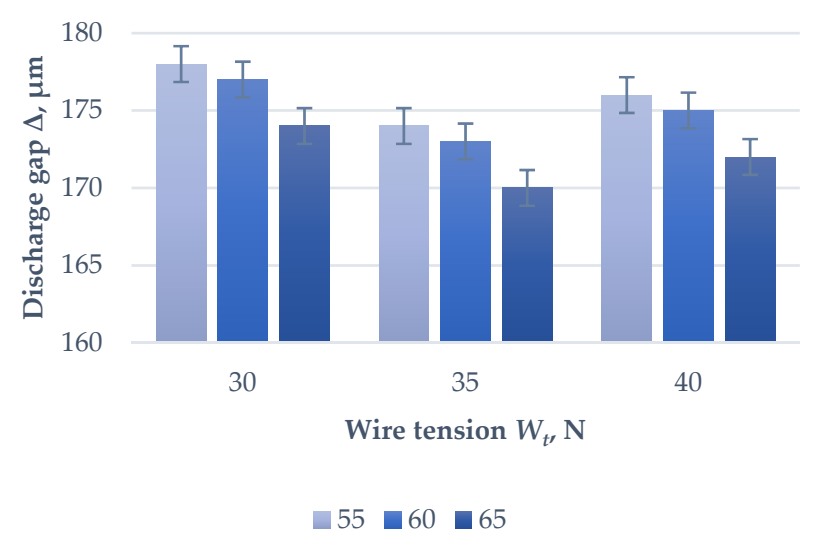

(a)

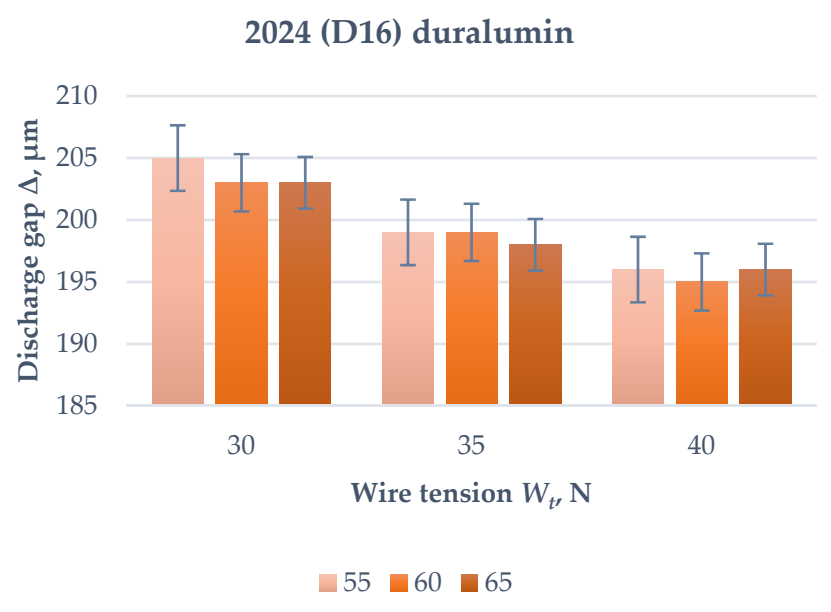

(b)

Figure 2. Histograms of the measured discharge gaps on electrical discharge machining factors $V_{o}$ and $W_{t}$ : (a) $\mathrm{X} 10 \mathrm{CrNiTi18-}$ 10 (12kH18N10T) steel; (b) D16 (AA2024) allo2024 (D16) duralumin.

\subsection{Surface Topology (Optical Microscopy)}

The topology of the samples after electrical discharge machining of both samples in water is presented in Figure 3. As can be seen, both of the samples have a typical "shagreen" type of surfaces with the differently spaced convexes of sublimated and recast material. The distance between surface convexes is 5-50 $\mu \mathrm{m}$ for the samples made of X10CrNiTi18-10 (12kH18N10T) steel and 10-100 $\mu \mathrm{m}$ for the samples made of 2024 (D16) duralumin. The formed convexes (flakes of secondary material) have an overall size of 7-35 $\mu \mathrm{m}$ for X10CrNiTi18-10 (12kH18N10T) steel and 15-45 $\mu \mathrm{m}$ for 2024 (D16) duralumin. The material surface presents a chaotically sublimated surface of the main material that was heat-affected by the discharge pulses and the convexes with the presence of formed complex secondary structure that has metallic luster for the samples made of X10CrNiTi18$10(12 \mathrm{kH} 18 \mathrm{~N} 10 \mathrm{~T})$ steel and black matte and metallic matte sheen for the samples made of 2024 (D16) duralumin. Both surfaces vary significantly from the well-known cut surfaces of the metals (grey glossy and grey matte). 


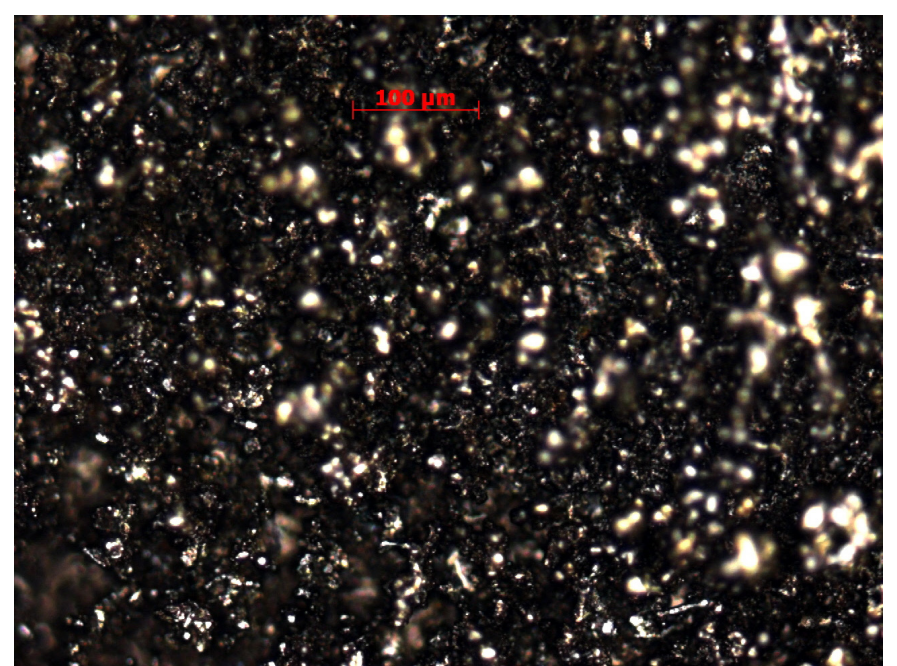

(a)

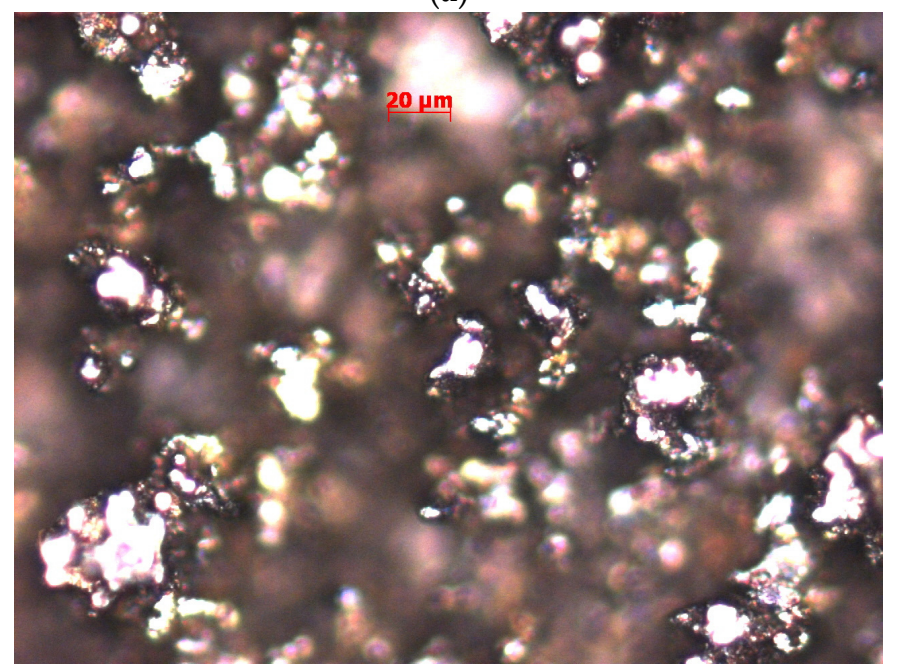

(c)

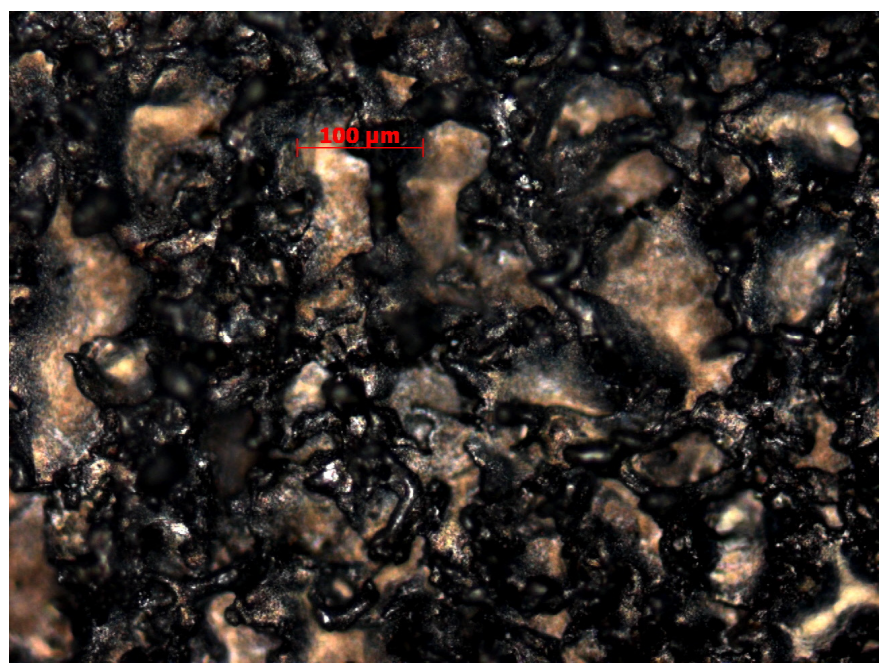

(b)

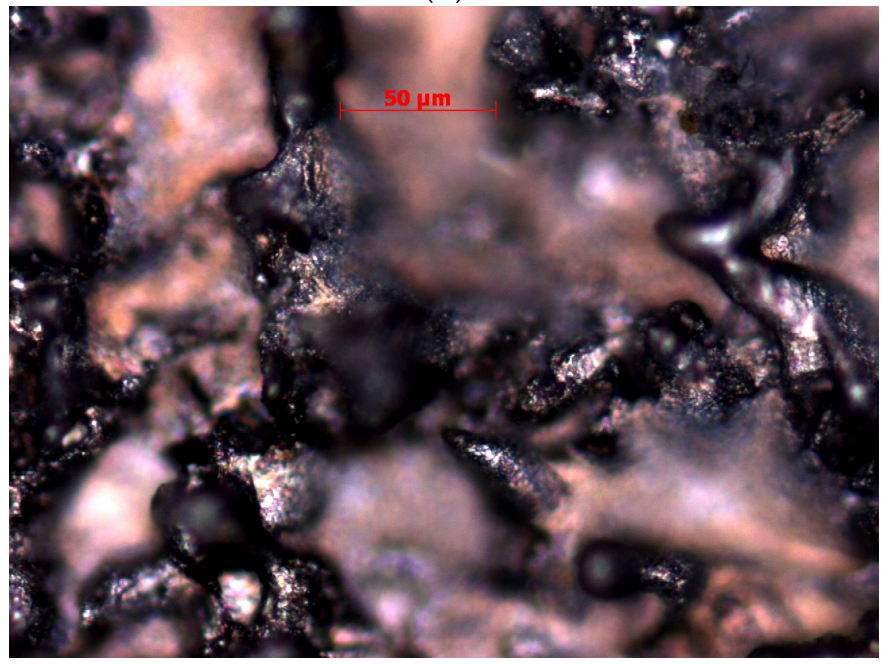

(d)

Figure 3. Topology the samples after electrical discharge machining with a brass wire tool electrode in water:

(a) X10CrNiTi18-10 (12kH18N10T) steel, 20×; (b) 2024 (D16) duralumin, 20×; (c) X10CrNiTi18-10 (12kH18N10T) steel, 50×;

(d) 2024 (D16) duralumin, $50 \times$.

\subsection{Chemical Nanomodification of the Surface Layer (X-ray Spectroscopy)}

The chemical analyses of the sample surface after electrical discharge machining by X-ray photoelectron spectroscopy are presented in Figures 4 and 5. Countable results are shown in Tables 5 and 6. Both of the surface layers have the presence of the chemical components of the wire tool and complex compounds of secondary order (metastable solid solution and/or eutectics).

Both samples show metallic $\mathrm{Zn}$ and copper oxide samples responsible for metallic grey and black sediment on the machined surfaces (Figure $4 a, b$ and Figure $5 a, b)$. Zn is bound in oxide (usually matte white film) (Figure 5a) in the duralumin sample. The quantity analyses confirmed the slight presence of wire tool electrode material (less than 4 at.\%). It should be noted that copper (1.4 at.\%) found on the X10CrNiTi18-10 (12kH18N10T) steel sample machined surface (Table 6) is 5.6 times more than the 2024 (D16) duralumin sample has ( 0.25 at.\%, Table 7$)$ despite the presence of $<5 \mathrm{wt} . \%$ of copper in the workpiece material (Table 4$)$. 


\section{Zn2p Scan}

20 Scans, $6 \mathrm{~m} 11.0 \mathrm{~s}, 400 \mu \mathrm{m}$, CAE 40.0

$0.10 \mathrm{eV}$

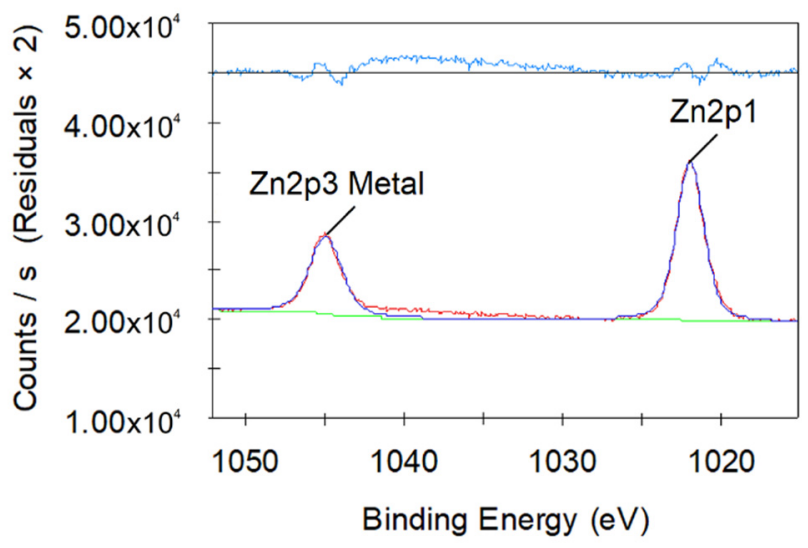

(a)

$\mathrm{Fe} 2 \mathrm{p}$ Scan

20 Scans, $6 \mathrm{~m} 41.0 \mathrm{~s}, 400 \mu \mathrm{m}, \mathrm{CAE} 40.0$

$0.10 \mathrm{eV}$

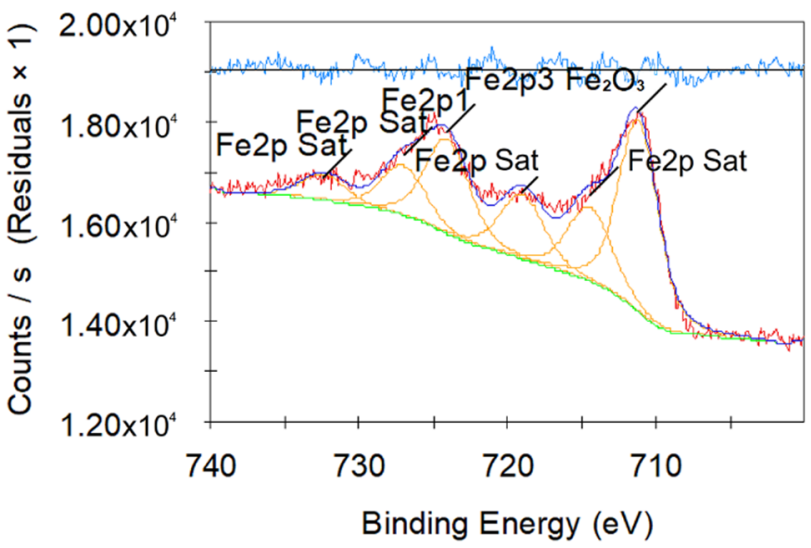

(c)

O1s Scan

20 Scans, $3 \mathrm{~m} 21.0 \mathrm{~s}, 400 \mu \mathrm{m}$, CAE 40.0

$0.10 \mathrm{eV}$

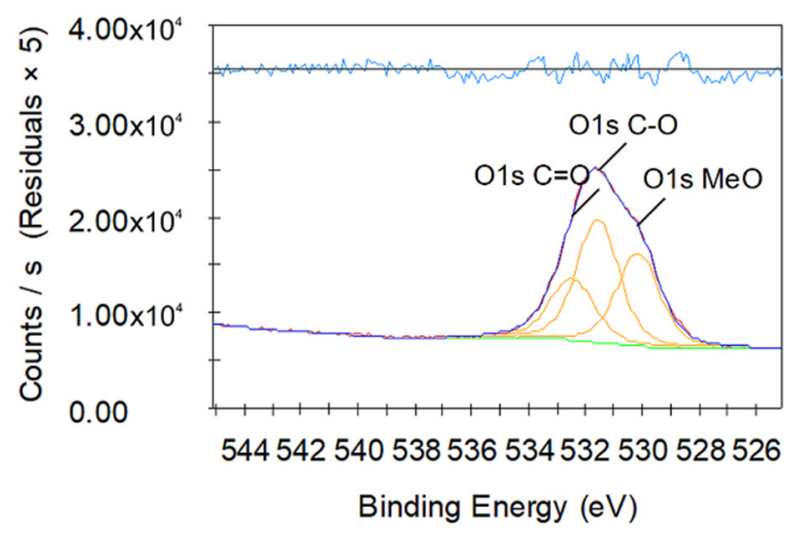

(e)
Cu2p Scan

20 Scans, $6 \mathrm{~m} 41.0 \mathrm{~s}, 400 \mu \mathrm{m}, \mathrm{CAE} 40.0$ $0.10 \mathrm{eV}$

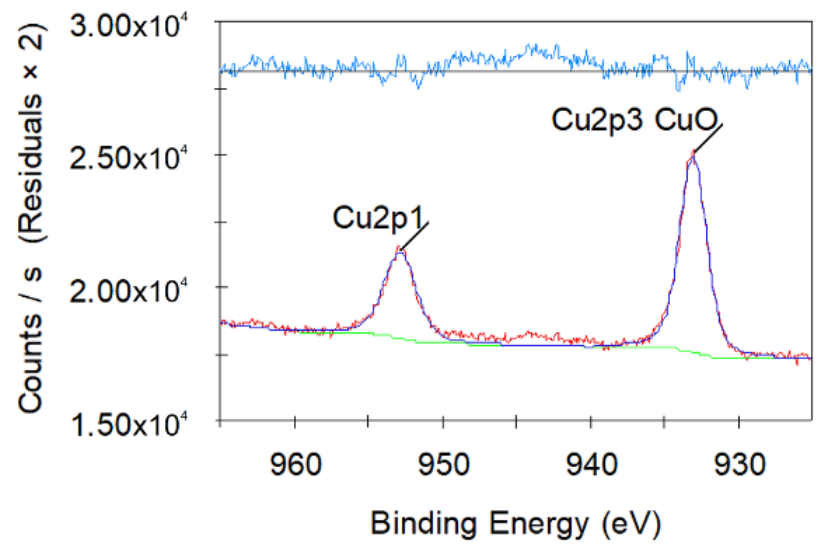

(b)

Cr2p Scan

20 Scans, $4 \mathrm{~m} 21.0 \mathrm{~s}, 400 \mu \mathrm{m}, \mathrm{CAE} 40.0$ $0.10 \mathrm{eV}$

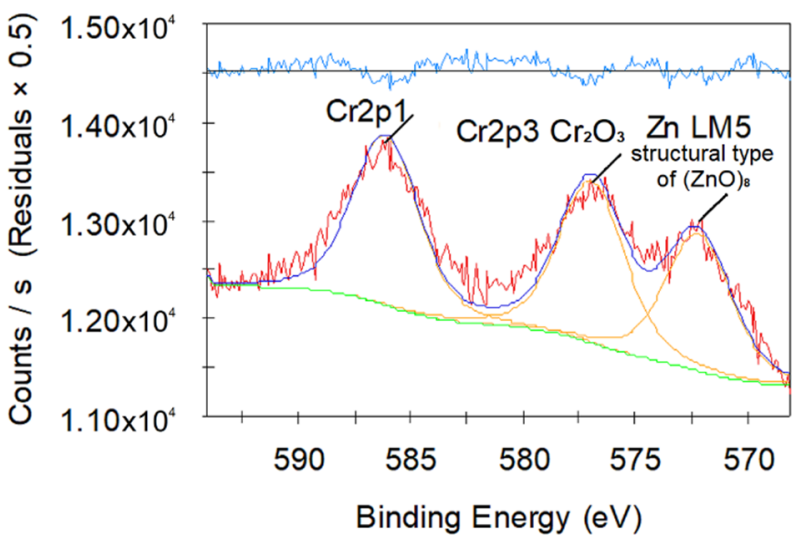

(d)

C1s Scan

20 Scans, $3 \mathrm{~m} 11.0 \mathrm{~s}, 400 \mu \mathrm{m}, \mathrm{CAE} 40.0$ $0.10 \mathrm{eV}$

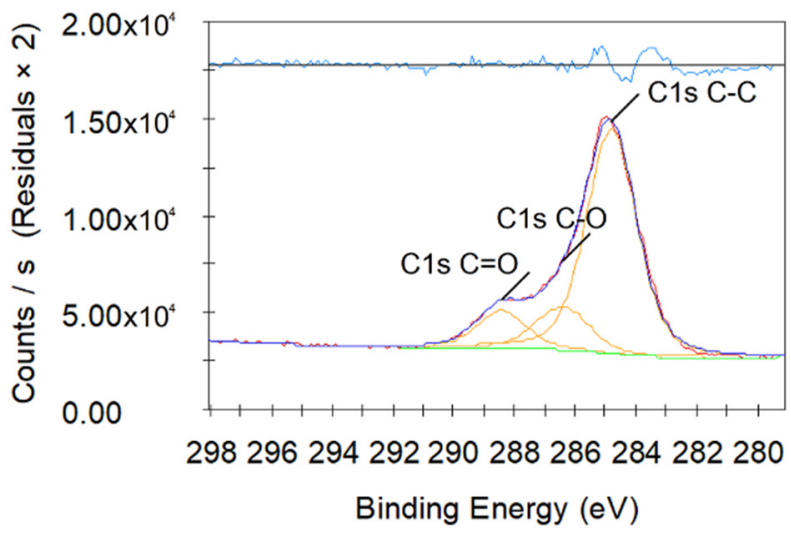

(f)

Figure 4. X-ray photoelectron spectroscopy of machined surfaces of X10CrNiTi18-10 (12kH18N10T) steel workpiece in water medium: (a) zinc; (b) copper; (c) iron; (d) chromium; (e) oxygen; (f) carbon. 


\section{Zn2p Scan}

20 Scans, $6 \mathrm{~m} 11.0 \mathrm{~s}, 400 \mu \mathrm{m}$, CAE 40.0

$0.10 \mathrm{eV}$

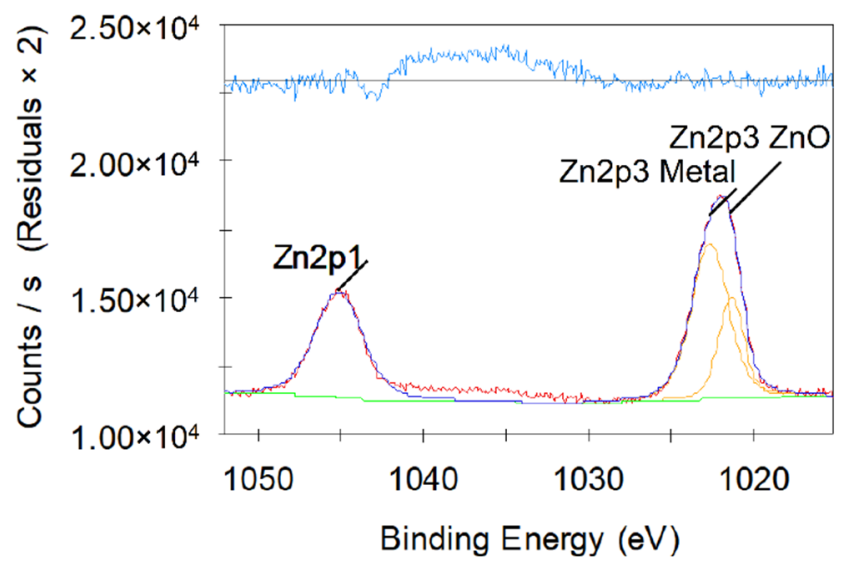

(a)

Al2p Scan

20 Scans, $3 \mathrm{~m} 21.0 \mathrm{~s}, 400 \mu \mathrm{m}, \mathrm{CAE} 40.0$

$0.10 \mathrm{eV}$

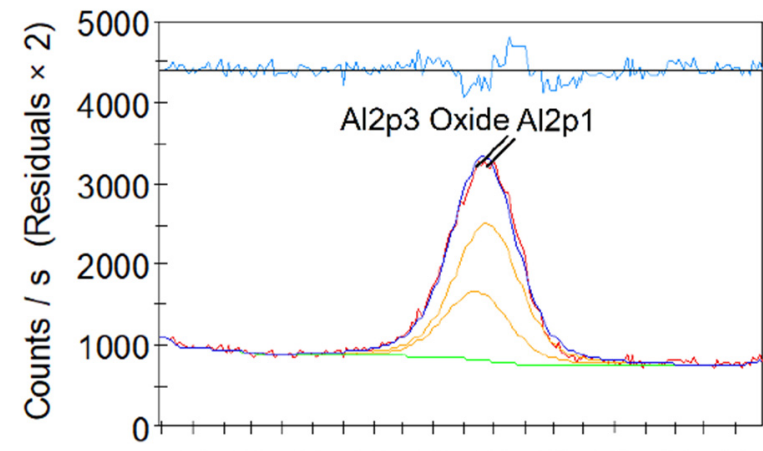

$\begin{array}{llllllllll}84 & 82 & 80 & 78 & 76 & 74 & 72 & 70 & 68 & 66\end{array}$

Binding Energy (eV)

(c)
Cu2p Scan

20 Scans, $6 \mathrm{~m} 41.0 \mathrm{~s}, 400 \mu \mathrm{m}, \mathrm{CAE} 40.0$

$0.10 \mathrm{eV}$

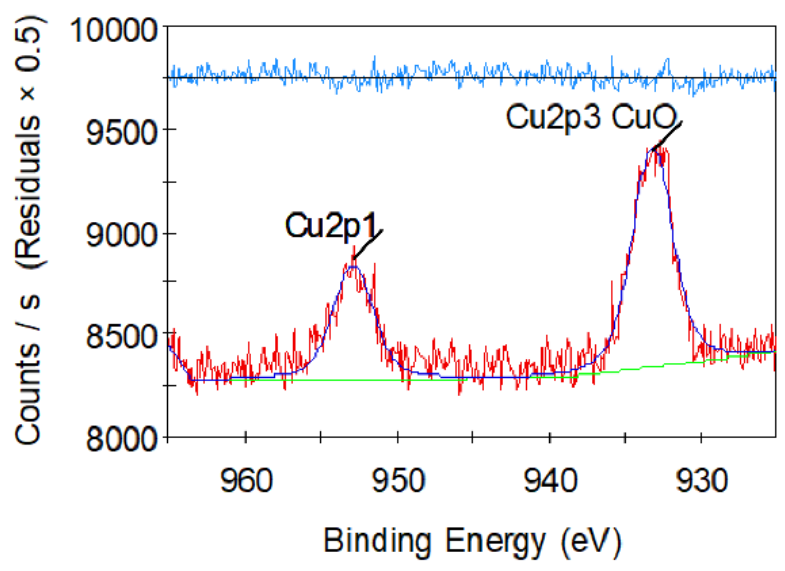

(b)

Cu2p Scan

20 Scans, $6 \mathrm{~m} 41.0 \mathrm{~s}, 400 \mu \mathrm{m}, \mathrm{CAE} 40.0$ $0.10 \mathrm{eV}$

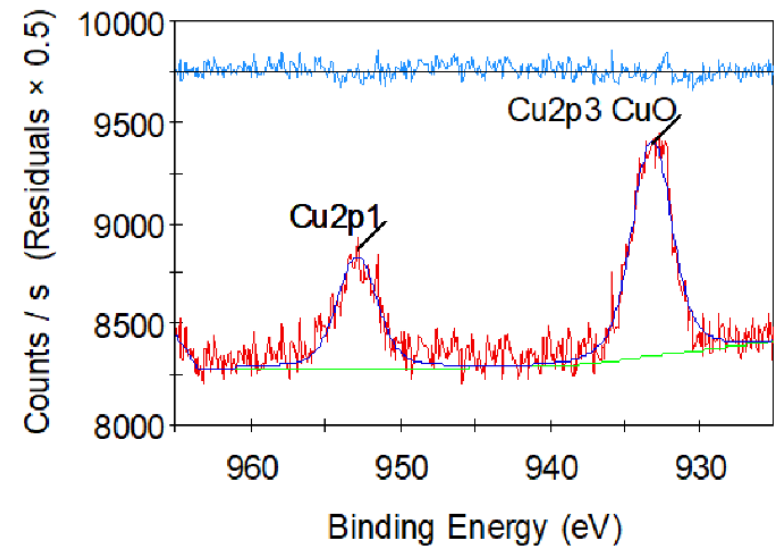

(d)

C1s Scan

20 Scans, $3 \mathrm{~m} 11.0 \mathrm{~s}, 400 \mu \mathrm{m}, \mathrm{CAE} 40.0$

$0.10 \mathrm{eV}$

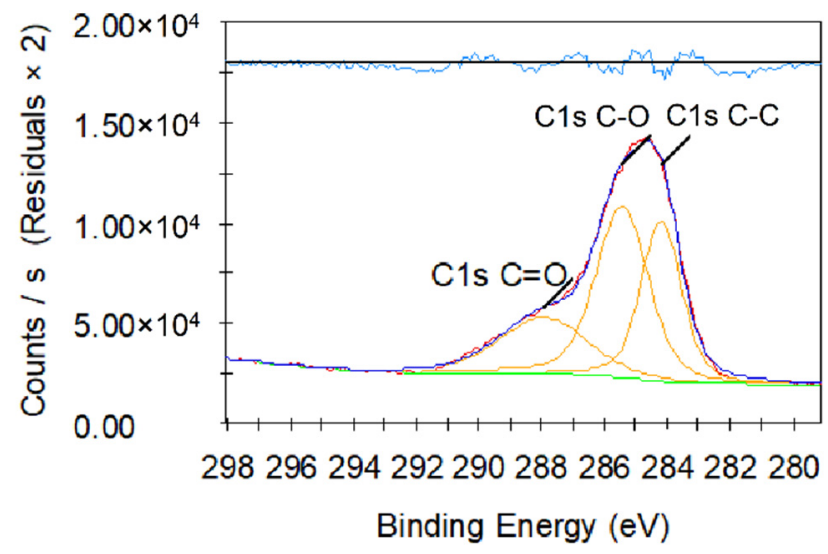

(e)

Figure 5. X-ray photoelectron spectroscopy of machined surfaces of 2024 (D16) duralumin workpiece in water medium: (a) zinc; (b) copper; (c) aluminum; (d) oxygen; (e) carbon. 
Table 6. X-ray peaks of the X10CrNiTi18-10 (12kH18N10T) steel sample machined surfaces.

\begin{tabular}{cccc}
\hline Chemical Element & Binding Energy $\boldsymbol{E}$ & $\begin{array}{c}\text { Peak of Binding } \\
\text { Energy, eV }\end{array}$ & Atomic \% \\
\hline Oxygen & $\mathrm{O} 1 \mathrm{~s}$ & 532.5 & 29.31 \\
Zinc & $\mathrm{Zn} 2 \mathrm{p} 3$ & 1022.7 & 3.44 \\
Carbon & $\mathrm{C} 1 \mathrm{~s}$ & 286.2 & 58.07 \\
Copper & $\mathrm{Cu} 2 \mathrm{p} 3$ & 934.3 & 1.4 \\
Iron & $\mathrm{Fe} 2 \mathrm{p}$ & 712.3 & 1.68 \\
Nitrogen & $\mathrm{N} 1 \mathrm{~s}$ & 400.8 & 2.21 \\
Magnesium & $\mathrm{Mg} 1 \mathrm{~s}$ & 1305.5 & 0.22 \\
Sodium & $\mathrm{Na} 1 \mathrm{~s}$ & 1072.4 & 0.51 \\
Chlorine & $\mathrm{Cl} 2 \mathrm{p}$ & 200.8 & 0.89 \\
Chromium & $\mathrm{Cr} 2 \mathrm{p}$ & 575.2 & 2.25 \\
\hline
\end{tabular}

Table 7. X-ray peaks of the 2024 (D16) duralumin sample machined surfaces.

\begin{tabular}{cccc}
\hline Chemical Element & Binding Energy $\boldsymbol{E}$ & $\begin{array}{c}\text { Peak of Binding } \\
\text { Energy, eV }\end{array}$ & Atomic \% \\
\hline Oxygen & O1s & 531.9 & 36.66 \\
Zinc & Zn2p3 & 1022.2 & 1.87 \\
Magnesium & Mg1s & 1304.3 & 4.38 \\
Carbon & $\mathrm{C} 1 \mathrm{~s}$ & 285 & 40.37 \\
Aluminum & $\mathrm{Al} 2 \mathrm{p}$ & 74.3 & 10.42 \\
Nitrogen & $\mathrm{N} 1 \mathrm{~s}$ & 400 & 2.59 \\
Calcium & $\mathrm{Ca} 2 \mathrm{p}$ & 352 & 2.12 \\
Copper & $\mathrm{Cu} 2 \mathrm{p} 3$ & 933.4 & 0.25 \\
Chlorine & $\mathrm{Cl2p} 3$ & 198.9 & 1.35 \\
\hline
\end{tabular}

X10CrNiTi18-10 (12kH18N10T) steel sample also demonstrates slight (less than 3 at.\%) presence of $\mathrm{Fe}_{2} \mathrm{O}_{3}$ and $\mathrm{Cr}_{2} \mathrm{O}_{3}$ oxides (Figure 4), while 2024 (D16) duralumin sample (Figure 5) is covered with $\mathrm{Al}_{2} \mathrm{O}_{3}$ film (10.42 at.\%) of the primary material. The rest of the workpiece material (66-70 wt.\% of Fe, 17-19 wt.\% of Cr for X10CrNiTi18-10 (12kH18N10T) steel; 91-95 wt.\% of $\mathrm{Al}$ for 2024 (D16) duralumin) was sublimated in the interelectrode gap in the form of debris.

$\mathrm{C}-\mathrm{C}, \mathrm{C}-\mathrm{O}$, and $\mathrm{C}=\mathrm{O}$ (Figures $4 \mathrm{f}$ and $5 \mathrm{e}$ ) bonds correspond to the atmospheric contamination of the samples: 58 at.\% bound carbon for X10CrNiTi18-10 (12kH18N10T) steel (Table 7) and $\sim 40$ at.\% bound carbon for 2024 (D16) duralumin (Table 7).

Some elements of the workpiece material such as $\mathrm{Ni}(<11 \mathrm{wt} . \%), \mathrm{Mn}(<2.0 \mathrm{wt} . \%)$, $\mathrm{Ti}(<0.8 \mathrm{wt} . \%)$, and $\mathrm{Si}(<0.8 \mathrm{wt} . \%)$ for X10CrNiTi18-10 (12kH18N10T) steel sample and Mn ( $<0.9$ wt. $\%)$, Fe $(<0.5$ wt.\%), and Si $(<0.5$ wt.\%) for 2024 (D16) duralumin sample are not presented in X-ray photoelectron spectroscopy data (Tables 6 and 7). However, other elements such as chlorine ( 0.89 at. \% for steel, 1.35 at.\% for duralumin), magnesium (0.22 at.\% for steel, 4.38 at.\% for duralumin), calcium (2.12 at.\% for duralumin), bonded nitrogen (2.21 at.\% for steel, 2.59 at.\% for aluminum) of water dielectric were deposed.

\section{Discussion}

The measured difference in the discharge gaps between two structural materials is related to their electrical properties. As can be seen from Table 5, they have values of specific electrical resistance differing by a factor of $\sim 14\left(0.725 \frac{\Omega \cdot \mathrm{mm}^{2}}{\mathrm{~m}}\right.$ for steel and $0.052 \frac{\Omega \cdot \mathrm{mm}^{2}}{\mathrm{~m}}$ for duralumin), which explains the difference in the discharge gap. Since duralumin is more conductive (electrical conductivity is the reciprocal of electrical resistance), the breakdown of the dielectric medium (deionized water) occurs at a greater distance than for stainless steel. According to generally accepted information about the typically recommended spark gaps for materials and electrical resistivity values, the lowest value of the conductive materials is listed for graphite, which also exhibits electrical anisotropy [56], and the highest values for listed for silver [57], metallic carbides (delocalized metal bond $d$-element 
carbides such as $\mathrm{Fe}_{\mathrm{x}} \mathrm{C}_{\mathrm{y}}, \mathrm{WC}, \mathrm{TiC}, \mathrm{V}_{\mathrm{x}} \mathrm{C}_{\mathrm{y}}, \mathrm{Cr}_{\mathrm{x}} \mathrm{C}_{\mathrm{y}}$, and $\mathrm{Ni}_{\mathrm{x}} \mathrm{C}$ ) [58,59], nitrides [60-62], and superconducting intermetallics [63]. The lowest values of the discharge gap correspond to the stable wire electrical discharge machining mode that allows more effective control of part geometry.

The elemental analyses showed that the quantity of zinc in the X10CrNiTi18-10 (12kH18N10T) steel sample is 1.84 times higher than that in the 2024 (D16) duralumin, which can be explained by chemical interaction between $\mathrm{Zn}$ of the wire and $\mathrm{Ni}$ in steel content. According to the theoretical prediction, it can be concluded that the $\mathrm{Ni}_{5} \mathrm{Zn}_{21}$ intermetallic compound (dark grey sediment) can be formed at the following ratio [55]:

$$
a^{N i^{2+}}: b^{Z n^{2+}}=1: 2 .
$$

Let us calculate the entropy of the intermetallic compound in the crystalline form:

$$
S_{i n t}^{c}=S_{N i}^{c} \cdot y_{N i}+S_{Z n}^{c} \cdot y_{Z n}-R^{\prime} \cdot\left[y_{N i} \cdot \ln y_{N i}+y_{Z n} \cdot \ln y_{Z n}\right]
$$

where $S_{\text {int }}^{c}$ is the entropy of the crystalline phase of $\mathrm{Ni}_{5} \mathrm{Zn}_{21}$ intermetallic compound, $\mathrm{J} /(\mathrm{mol} \cdot \mathrm{K})$; $S^{c}$ is the entropy of the crystalline phase of the intermetallic compound components, $\mathrm{J} /(\mathrm{mol} \cdot \mathrm{K})$; $y$ is the molar fraction of the components, $\mathrm{mol} ; R=8.31446261815324 \mathrm{~J} /(\mathrm{mol} \cdot \mathrm{K})$; and the gas constant for a specific gas is $R^{\prime}=\frac{R}{M}$, where $M$ is the molar mass of $\mathrm{Ni}_{5} \mathrm{Zn}_{21}$ of $1.667 \mathrm{~kg} / \mathrm{mol}$. Then,

$$
S_{\text {int }}^{c}=29.9 \cdot 5.0+41.6 \cdot 21.0-\frac{8.314}{1.667} \cdot[5.0 \cdot \ln 5.0+21.0 \cdot \ln 21.0]=664.10\left[\frac{\mathrm{J}}{\mathrm{mol} \cdot \mathrm{K}}\right] .
$$

The entropy of the intermetallic compound formation is determined by the Boltzmann equation taking into account the Stirling theory and the corollary of Hess's law [64]:

$$
\Delta S_{i n t}^{0}=-R^{\prime} \cdot\left[y_{N i} \cdot \ln y_{N i}+y_{Z n} \cdot \ln y_{Z n}\right]=-\frac{8.314}{1.667} \cdot[5.0 \cdot \ln 5.0+21.0 \cdot \ln 21.0]=-359.00\left[\frac{\mathrm{J}}{\mathrm{mol} \cdot \mathrm{K}}\right] \text {. }
$$

when entropy is less than zero, reactions occur with a decrease in the degree of chaos (solidification).

The empirical value of electronegativities can be used to estimate the standard heats (enthalpy) of the formation of ionic and metallic compounds with the accuracy of $13.8-20.4 \%$ for intermetallics:

$$
\Delta H_{298}^{0}=-23.066 \cdot z \cdot\left(\varepsilon_{A}-\varepsilon_{B}\right)^{2}\left[\frac{\mathrm{kkal}}{\mathrm{mol}}\right]
$$

or

$$
\Delta H_{298}^{0}=-96.623 \cdot z \cdot\left(\varepsilon_{A}-\varepsilon_{B}\right)^{2}\left[\frac{\mathrm{kJ}}{\mathrm{mol}}\right] .
$$

where $\Delta H_{298}^{0}$ is the standard enthalpy of formation, $\mathrm{kJ} / \mathrm{mol} ; z$ is a number of valence bonds; and $\varepsilon_{A}$ and $\varepsilon_{B}$ are empirical values of electronegativities that are 1.8 for $\mathrm{Ni}$ and 1.5 for $\mathrm{Zn}$. The number of metallic bonds in the compound is

$$
z=5+21=26
$$

then

$$
\Delta H_{298}^{0}\left(\mathrm{Ni}_{5} \mathrm{Zn} n_{21}\right)=-4.189 \cdot 23.066 \cdot 26 \cdot(1.8-1.5)^{2}=-225.96\left[\frac{\mathrm{kJ}}{\mathrm{mol}}\right] .
$$

Gibbs energy will be

$$
\Delta G_{T}^{0}\left(N i_{5} Z n_{21}\right)=\Delta H_{298}^{0}-T \cdot \Delta S_{\text {int }}^{0}=-225.96-298 \cdot(-0.359)=-118.98\left[\frac{\mathrm{kJ}}{\mathrm{mol}}\right] .
$$


when $\Delta G_{T}^{0}<0$, the reaction at normal temperature $(298 \mathrm{~K})$ is possible in the forward direction from sublimated ions of metals, and the presence of high heat in the discharge channel (any other source of high heat such as laser beam or bombarding by fast atoms $[65,66]$ ) can only accelerate $\mathrm{Ni}_{5} \mathrm{Zn}_{21}$ ( $\gamma$-phase) solidification. The oxide film formed on the transition metals can prevent the direct reaction under normal conditions. The practice shows that the reaction of $\mathrm{Ni}$ with $\mathrm{Zn}$ at temperatures above $1000{ }^{\circ} \mathrm{C}$ (melting points are $1453{ }^{\circ} \mathrm{C}$ for $\mathrm{Ni}, 419.6{ }^{\circ} \mathrm{C}$ for $\mathrm{Zn}, 1682{ }^{\circ} \mathrm{C}$ for $\mathrm{NiO}$, and $1975{ }^{\circ} \mathrm{C}$ for $\mathrm{ZnO}$; boiling point of $\mathrm{Zn}$ is $906.2^{\circ} \mathrm{C}$ (Table 5)) has an explosive character and is accompanied by a series of sparks in the discharge gap $[51,67]$ that can be even acoustically monitored and registered [1]. The thermochemical calculations are presented in Table 8.

Table 8. Calculated enthalpy of formation of some $\mathrm{Zn}$ - and Ni-containing substances.

\begin{tabular}{|c|c|c|c|c|}
\hline Chemical Reaction & $\begin{array}{c}\text { Chemical } \\
\text { Composition of } \\
\text { Erosion Product }\end{array}$ & $\begin{array}{l}\text { Amount of Substance } \\
n[\mathrm{~mol}]\end{array}$ & $\begin{array}{c}\text { Enthalpy of } \\
\text { Substances } \Delta H^{0}{ }_{298} \\
{\left[\mathrm{~kJ} \cdot \mathrm{mol}^{-1}\right]}\end{array}$ & $\begin{array}{l}\text { Enthalpy of Formation } \\
\qquad \Delta H^{0}{ }_{T}[\mathrm{~kJ}]\end{array}$ \\
\hline (2) & $\mathrm{Zn}(\mathrm{OH})_{2}$ & $1+2 \stackrel{T}{\rightarrow} 1+1$ & $0-285.8 \stackrel{T}{\rightarrow}-645.4+0$ & $\begin{array}{c}{[1 \cdot(-645.4)+1 \cdot 0]-} \\
{[1 \cdot 0+2 \cdot(-285.8)]=-73.8}\end{array}$ \\
\hline (3) & $\mathrm{ZnO}$ & $1+1 \stackrel{T}{\rightarrow} 1+1$ & $0-285.8 \stackrel{T}{\rightarrow}-350.8+0$ & $\begin{array}{c}{[1 \cdot(-350.8)+1 \cdot 0]-} \\
{[1 \cdot 0+1 \cdot(-285.8)]=-65.0}\end{array}$ \\
\hline (4) & $\mathrm{NiO}$ & $1+1 \stackrel{T}{\rightarrow} 1+1$ & $0-285.8 \stackrel{T}{\rightarrow}-239.7+0$ & $\begin{array}{c}{[1 \cdot(-239.7)+1 \cdot 0]-} \\
{[1 \cdot 0+1 \cdot(-285.8)]=46.1}\end{array}$ \\
\hline
\end{tabular}

The enthalpy of the formation for reactions (2) and (3) is less than zero; thus, these reactions spontaneously take place with the release of heat, in contrast to the reaction with nickel (4). Table 9 shows the calculated entropy, Gibbs energy, and equilibrium temperature for mentioned reactions.

Table 9. Calculated entropy of some $\mathrm{Zn}$ - and Ni-containing substances and equilibrium temperatures.

\begin{tabular}{|c|c|c|c|c|c|}
\hline $\begin{array}{l}\text { Chemical } \\
\text { Reaction }\end{array}$ & $\begin{array}{c}\text { Amount of } \\
\text { Substance } n \text { [mol] }\end{array}$ & $\begin{array}{c}\text { Entropy of Substances } \\
\Delta S^{0}{ }_{298}\left[\mathrm{~J} \cdot \mathrm{mol}^{-1}\right]\end{array}$ & Entropy of Formation $\Delta S^{0}{ }_{T}[\mathrm{~J}]$ & Gibbs Energy $\Delta G^{0}{ }_{298}\left[\mathrm{~kJ} \cdot \mathrm{mol}^{-1}\right]$ & $\begin{array}{c}\text { Equilibrium } \\
\text { Temperature } T[\mathrm{~K}]\end{array}$ \\
\hline (2) & $1+2 \stackrel{T}{\rightarrow} 1+1$ & $\begin{array}{l}41.6+70.1 \stackrel{T}{\rightarrow} \\
77.0+130.52\end{array}$ & $\begin{array}{c}{[1 \cdot 77.0+1 \cdot 130.52]-} \\
{[1 \cdot 41.6+2 \cdot 70.1]=25.72}\end{array}$ & $-73.8-298 \cdot 0.02572=-81.46$ & $\frac{|73.8|}{0.02572}=2869.36$ \\
\hline (3) & $1+1 \stackrel{T}{\rightarrow} 1+1$ & $\begin{array}{l}41.6+70.1 \stackrel{T}{\rightarrow} \\
43.6+130.52\end{array}$ & $\begin{array}{c}{[1 \cdot 43.6+1 \cdot 130.52]-} \\
{[1 \cdot 41.6+1 \cdot 70.1]=62.42}\end{array}$ & $-65.0-298 \cdot 0.06242=-83.60$ & $\frac{|65.0|}{0.06242}=1041.33$ \\
\hline (4) & $1+1 \stackrel{T}{\rightarrow} 1+1$ & $\begin{array}{l}29.9+70.1 \stackrel{T}{\rightarrow} \\
38.0+130.52\end{array}$ & $\begin{array}{c}{[1 \cdot 38.0+1 \cdot 130.52]-} \\
{[1 \cdot 29.9+1 \cdot 70.1]=68.52}\end{array}$ & $46.1-298 \cdot 0.06852=25.68$ & $\frac{|46.1|}{0.06852}=672.80$ \\
\hline
\end{tabular}

In all reactions, the entropy is more than zero, corresponding to an increase in the degree of chaos (evaporation). That can be confirmed by the appearance of gas bubbles in the discharge gap observed during electrical discharge machining with a brass tool electrode and/or with a nickel-containing workpiece in a water medium. The calculated Gibbs energies for reactions (2) and (3) are almost similar when the entropy of formation is higher for $\mathrm{ZnO}$ formation. This means that reaction (3) is more probable than (2) in identical conditions. At the same time, $\Delta G^{0}{ }_{298}$ of reaction (4) is above zero despite having higher entropy of formation than (3). This means that the reaction at normal conditions can only pass in the opposite direction and the formation of nickel oxide occurs with heat absorption only when heated to equilibrium temperatures ( $672.8 \mathrm{~K})$. Thus, the reaction of $\mathrm{Ni}$ and $\mathrm{Zn}$ is more likely with the presence of nickel (Figure 6). 


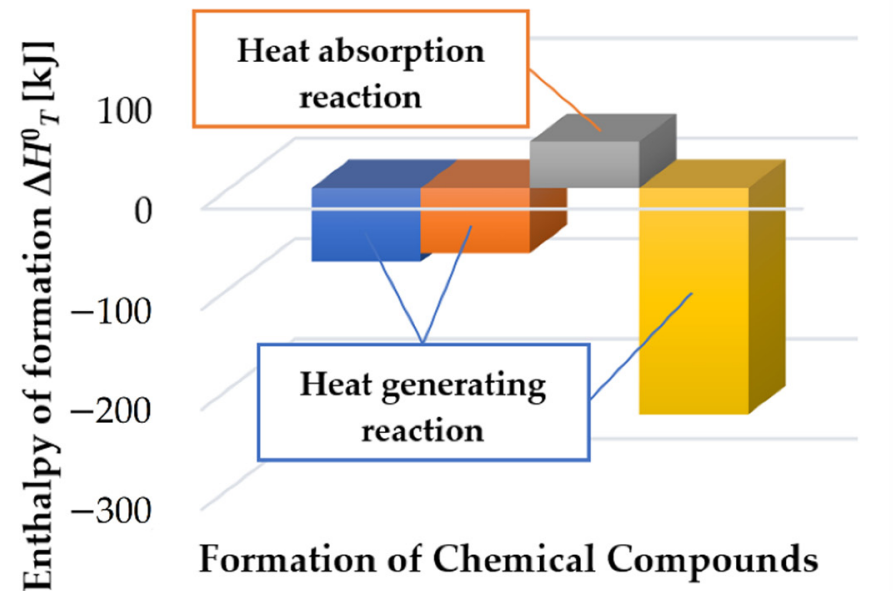

$\square \mathrm{Zn}(\mathrm{OH})_{2} \quad \square \mathrm{ZnO} \quad \square \mathrm{NiO} \quad \mathrm{Ni}_{5} \mathrm{Zn}_{21}$

(a)

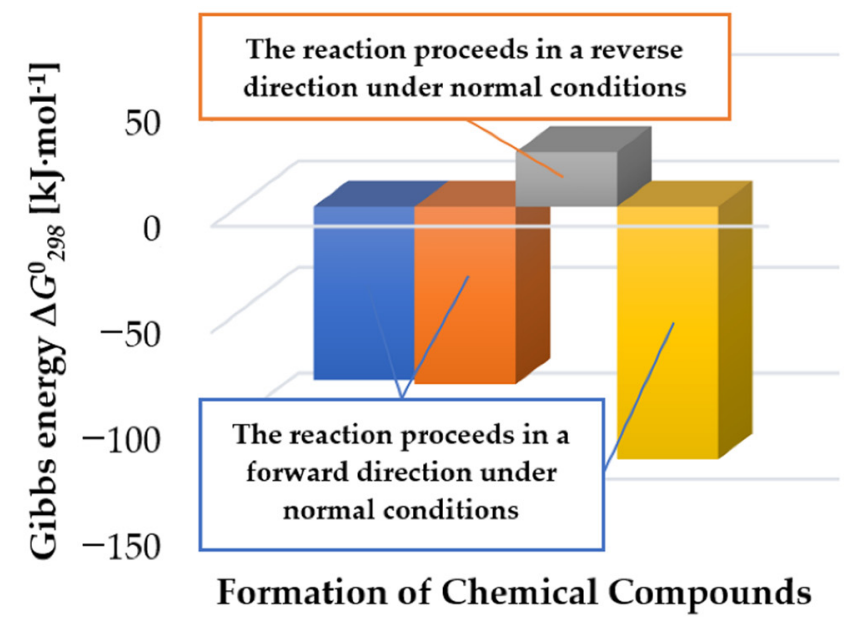

$\square \mathrm{Zn}(\mathrm{OH})_{2} \quad \square \mathrm{ZnO} \quad \square \mathrm{NiO} \quad \mathrm{Ni}_{5} \mathrm{Zn}_{21}$

(c)

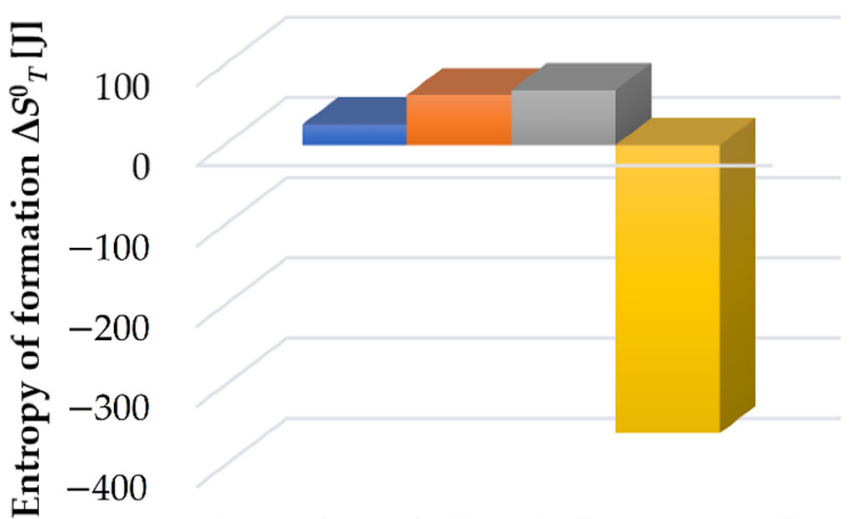

Formation of Chemical Compounds

$\square \mathrm{Zn}(\mathrm{OH})_{2} \quad \square \mathrm{ZnO} \quad \square \mathrm{NiO} \quad \mathrm{Ni}_{5} \mathrm{Zn}_{21}$

(b)

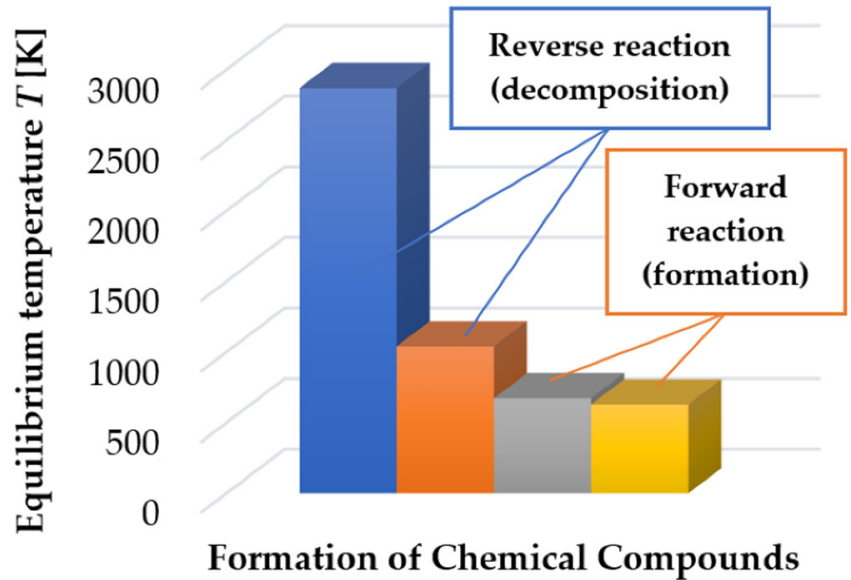

$\square \mathrm{Zn}(\mathrm{OH})_{2} \quad \square \mathrm{ZnO} \quad \square \mathrm{NiO} \quad \square \mathrm{Ni}_{5} \mathrm{Zn}_{21}$

(d)

Figure 6. Thermochemical parameters of chemical reactions of nickel and zinc in a water medium: (a) enthalpy of formation; (b) entropy of formation; (c) Gibbs energy; (d) equilibrium temperatures.

\section{Conclusions}

The obtained data demonstrate the potential for nanomodification of the surface sample layer by using different machining processes' components and controlling it by choosing the working fluid and material of the electrode tool. Such modifications can promote the formation of a fragile sublayer for easier mechanical or electrochemical removal for the products where the recast layer is undesired or, on the contrary, strengthen the sublayer to improve wear resistance of the working surfaces of the product.

The nickel present in stainless steel improves the electrical conditions in the interelectrode gap, but not enough to be comparable to the more electrically conductive material, duralumin. Further research will be devoted to the elemental and thermochemical study of two materials with similar compositions and different nickel contents when treated with a brass electrode in water or hydrocarbons. 
The thermochemical analyses of the chemical reactions that occurred during solidification of sublimated material components showed that the formation of $\mathrm{ZnO}$ is more likely than that of $\mathrm{Zn}(\mathrm{OH})_{2}$ in the presence of $\mathrm{Zn}$ of the brass tool electrode and that the formation of $\mathrm{Ni}_{5} \mathrm{Zn}_{21}$ is more likely than that of $\mathrm{NiO}$ in the presence of $\mathrm{Zn}$ of the brass tool and Ni-containing workpiece (chrome-nickel stainless steel of austenite class). The calculated standard enthalpy of $\mathrm{Ni}_{5} \mathrm{Zn}_{21}$ formation is $-225.96\left[\frac{\mathrm{kJ}}{\mathrm{mol}}\right]$, the entropy of the crystalline phase is $424.64\left[\frac{\mathrm{J}}{\mathrm{mol} \cdot \mathrm{K}}\right]$, and the equilibrium temperature is $629.42 \mathrm{~K}$.

The obtained data have a fundamental character as the developed method can be recommended for industrial applications in the more proper choice of the tool electrode material for electrical discharge machining design in the context of structural requirements for the final product working surfaces to improve their functionality in the actual conditions of exploitation.

Author Contributions: Conceptualization, S.N.G.; methodology, S.N.G.; software, S.V.F., K.H.; validation, K.H.; formal analysis, S.V.F.; investigation, P.A.P.; resources, S.V.F.; data curation, P.A.P., K.H.; writing—original draft preparation, A.A.O.; writing—review and editing, A.A.O., M.A.V.; visualization, P.A.P., A.A.O.; supervision, M.A.V.; project administration, M.A.V.; funding acquisition, S.N.G. All authors have read and agreed to the published version of the manuscript.

Funding: This research was funded by a grant from the Russian Science Foundation, project No. 21-19-00790. The work was carried out on the equipment of the Center of Collective Use of MSUT "STANKIN".

Institutional Review Board Statement: Not applicable.

Informed Consent Statement: Not applicable.

Data Availability Statement: Data available in a publicly accessible repository.

Acknowledgments: The authors thank M.P. Kozochkin for his contribution to developing engineering processes' diagnosing and monitoring systems.

Conflicts of Interest: The authors declare no conflict of interest.

Nomenclature of Used Symbols:

\begin{tabular}{|c|c|c|c|}
\hline \multirow[t]{6}{*}{ Type } & Symbol & Description & Unit \\
\hline & $V_{o}$ & Operational voltage & V \\
\hline & $V_{g}$ & Auxiliary voltage & V \\
\hline & $I^{\circ}$ & Operational current strength & A \\
\hline & $I_{a}$ & Auxiliary current strength & A \\
\hline & $T_{\text {off }}$ & Time off ratio & $\%$ \\
\hline \multirow[t]{7}{*}{ Machine factors } & $T_{i}$ & Intermittent pause time & $\mu \mathrm{s}$ \\
\hline & $R_{f}$ & Wire feed rate & $\mathrm{mm} / \mathrm{min}$ \\
\hline & $R_{r}$ & Wire rewinding rate & $\mathrm{m} / \mathrm{min}$ \\
\hline & $W_{t}$ & Wire tension & $\mathrm{N}$ \\
\hline & $F_{d}$ & Dielectric pressure in nozzles & $\mathrm{Pa}$ \\
\hline & $\Delta$ & Discharge gap & $\mu \mathrm{m}$ \\
\hline & $\rho$ & Specific electrical resistance & $\frac{\Omega \cdot \mathrm{mm}^{2}}{\mathrm{~m}}$ \\
\hline \multirow[t]{7}{*}{ Material properties } & $T_{m}$ & Melting point & ${ }^{\circ} \mathrm{C}^{\mathrm{m}}$ \\
\hline & $T_{d}$ & Decomposition point & ${ }^{\circ} \mathrm{C}$ \\
\hline & $n, a^{N i^{2+}}, b^{\mathrm{Zn}^{2+}}$ & Amount of substance & mol \\
\hline & $y_{N i}, y_{Z n}$ & Molar fraction of components & mol \\
\hline & & Number of valence bonds & - \\
\hline & $\varepsilon_{A}, \varepsilon_{B}$ & Empirical values of electronegativities & $\mathrm{eV}$ \\
\hline & $R$ & Gas constant, $R=8.31446261815324$ & $\mathrm{~J} /(\mathrm{mol} \cdot \mathrm{K})$ \\
\hline \multirow{7}{*}{ Thermochemistry parameters } & $R^{\prime}$ & Gas constant for a specific gas & $\mathrm{J} /(\mathrm{mol} \cdot \mathrm{K})$ \\
\hline & M & Molar mass & $\mathrm{kg} / \mathrm{mol}$ \\
\hline & $S_{i n t,}^{c}, S_{N i}^{c}, S_{Z n}^{c}$ & Entropy of crystalline phase & $\mathrm{J} /(\mathrm{mol} \cdot \mathrm{K})$ \\
\hline & $\Delta S_{T}^{0}, \Delta S_{298}^{0}$ & Entropy of formation & $\mathrm{J} / \mathrm{mol}$ \\
\hline & $\Delta H_{T}^{0}, \Delta H_{298}^{0}$ & Enthalpy of formation (at a pressure of 1 atmosphere) & $\mathrm{kJ} / \mathrm{mol}$ \\
\hline & $\Delta G_{T}^{0}, \Delta G_{298}^{0}$ & Gibbs energy & $\mathrm{kJ} / \mathrm{mol}$ \\
\hline & $T$ & Equilibrum temperature & K \\
\hline
\end{tabular}




\section{References}

1. Grigoriev, S.N.; Kozochkin, M.P.; Kropotkina, E.Y.; Okunkova, A.A. Study of wire tool-electrode behavior during electrical discharge machining by vibroacoustic monitoring. Mech. Ind. 2016, 17, 717. [CrossRef]

2. Mouralova, K.; Zahradnicek, R.; Benes, L.; Prokes, T.; Hrdy, R.; Fries, J. Study of Micro Structural Material Changes after WEDM Based on TEM Lamella Analysis. Metals 2020, 10, 949. [CrossRef]

3. Chaudhari, R.; Vora, J.J.; Patel, V.; De Lacalle, L.N.L.; Parikh, D.M. Surface Analysis of Wire-Electrical-Discharge-MachiningProcessed Shape-Memory Alloys. Materials 2020, 13, 530. [CrossRef] [PubMed]

4. Gavrin, V.N.; Kozlova, Y.P.; Veretenkin, E.P.; Logachev, A.V.; Logacheva, A.I.; Lednev, I.S.; Okunkova, A.A. Reactor target from metal chromium for "pure" high-intensive artificial neutrino source. Phys. Part. Nucl. Lett. 2016, 13, 267-273. [CrossRef]

5. Gusev, V.N.; Rozhkov, L.A. Anodic Dissolution of Metal in Small Interelectrode Gaps with Forced Pumping of Electrolyte (Anodnoye rastvoreniye metalla v mezhelektrodnykh malykh zazorakh s prinuditel'noy prokachkoy elektrolita). U.S. Patent 28,384, 21 March 1928.

6. Davydov, A.D. Mechanism of Localization of Anodic Solution of Metal During Electrochemical Machining. Russ. J. Electrochem. 1975, 11, 751-752.

7. Grodzinskii, E.Y.; Zubatova, L.S. Electrochemical and Electrical-Discharge Abrasive Machining. Sov. Eng. Res. 1982, 2, 90-92.

8. Linovsky, A.V.; Fedorov, A.A.; Tignibidin, A.V.; Takauk, S.V.; Lavrentev, S.V. Investigation of the accuracy of gears produced by electrical discharge machining. Dyn. Syst. Mech. Mach. 2018, 6, 012081. [CrossRef]

9. Werner, A. Method for enhanced accuracy in machining curvilinear profiles on wire-cut electrical discharge machines. Precis. Eng. 2016, 44, 75-80. [CrossRef]

10. Lukashenko, S.V.; Kovtun, A.V.; Dashuk, P.N.; Sokolov, B.N. Method of Electrical Discharge Machining of Dielectrics. U.S. Patent 1,542,715, 10 December 1986.

11. Rashid, A.; Bilal, A.; Liu, C.; Jahan, M.P.; Talamona, D.; Perveen, A. Effect of Conductive Coatings on Micro-Electro-Discharge Machinability of Aluminum Nitride Ceramic Using On-Machine-Fabricated Microelectrodes. Materials 2019, 12, 3316. [CrossRef] [PubMed]

12. Tani, T.; Fukuzawa, Y.; Mohri, N.; Saito, N.; Okada, M. Machining phenomena in WEDM of insulating ceramics. J. Mater. Process. Technol. 2004, 149, 124-128. [CrossRef]

13. Kucukturk, G.; Cogun, C. A new method for machining of electrically nonconductive workpieces using electric discharge machining technique. Mach. Sci. Technol. 2010, 14, 189-207. [CrossRef]

14. Volosova, M.A.; Okunkova, A.A.; Fedorov, S.V.; Hamdy, K.; Mikhailova, M.A. Electrical Discharge Machining Non-Conductive Ceramics: Combination of Materials. Technologies 2020, 8, 32. [CrossRef]

15. Movchan, B.A.; Grechanyuk, N.I. Microhardness and Microbrittleness of Condensates of The Tic-Al2O3 System. Inorg. Mater. 1981, 17, 972-973.

16. Tran, T.-H.; Nguyen, M.-C.; Luu, A.-T.; Do, T.-V.; Le, T.-Q.; Vu, T.-T.; Tran, N.-G.; Do, T.-T.; Vu, N.-P. Electrical Discharge Machining with SiC Powder-Mixed Dielectric: An Effective Application in the Machining Process of Hardened 90CrSi Steel. Machines 2020, 8, 36. [CrossRef]

17. Jeswani, M.L. Effect of the addition of graphite powder to kerosene used as the dielectric fluid in EDM. Wear 1981, 70, 133-139. [CrossRef]

18. Zhang, W.; Li, L.; Wang, N.; Teng, Y. Machining of 7Cr13Mo steel by US-PMEDM process. Mater. Manuf. Process. $2021,1-7$.

19. Tzeng, Y.-F.; Lee, C.-Y. Effects of Powder Characteristics on Electrodischarge Machining Efficiency. Int. J. Adv. Manuf. Technol. 2001, 17, 586-592. [CrossRef]

20. Kumar, A.; Mandal, A.; Dixit, A.R.; Das, A.K. Performance evaluation of $\mathrm{Al}_{2} \mathrm{O}_{3}$ nano powder mixed dielectric for electric discharge machining of Inconel 825. Mater. Manuf. Process. 2018, 33, 986-995. [CrossRef]

21. Machno, M. Investigation of the Machinability of the Inconel 718 Superalloy during the Electrical Discharge Drilling Process Materials 2020, 13, 3392. [CrossRef] [PubMed]

22. Karmiris-Obratański, P.; Zagórski, K.; Papazoglou, E.L.; Markopoulos, A.P. Surface texture and integrity of electrical discharged machined titanium alloy. Int. J. Adv. Manuf. Technol. 2020, 1-15. [CrossRef]

23. Samanta, A.; Sekh, M.; Sarkar, S. Influence of different control strategies in wire electrical discharge machining of varying height job. Int. J. Adv. Manuf. Technol. 2016, 100, 1299-1309. [CrossRef]

24. Vereschaka, A.S.; Grigoriev, S.N.; Tabakov, V.; Sotova, E.S.; Vereschaka, A.A.; Kulikov, M.Y. Improving the Efficiency of the Cutting Tool Made of Ceramic when Machining Hardened Steel by Applying Nano-Dispersed Multi-Layered Coatings. Key Eng. Mater. 2013, 581, 68-73. [CrossRef]

25. Vereschaka, A.; Tabakov, V.; Grigoriev, S.; Aksenenko, A.; Sitnikov, N.; Oganyan, G.; Seleznev, A.; Shevchenko, S. Effect of adhesion and the wear-resistant layer thickness ratio on mechanical and performance properties of $\mathrm{ZrN}-(\mathrm{Zr}, \mathrm{Al}, \mathrm{Si}) \mathrm{N}$ coatings. Surf. Coat. Technol. 2019, 357, 218-234. [CrossRef]

26. Belhocine, A.; Bouchetara, M. Thermomechanical behavior of dry contacts in disc brake rotor with a grey cast iron composition. Therm. Sci. 2013, 17, 599-609. [CrossRef]

27. Kuzin, V.V.; Grigoriev, S.N.; Fedorov, M.Y. Role of the thermal factor in the wear mechanism of ceramic tools. Part 2: Microlevel. J. Frict. Wear 2015, 36, 40-44. [CrossRef] 
28. Lazarenko, B.R.; Lazarenko, N.I. Electric spark machining of metals in water and electrolytes. Surf. Eng. Appl. Electrochem. 1980, $1,5-8$.

29. Smith, C.; Koshy, P. Applications of acoustic mapping in electrical discharge machining. CIRP Ann. 2013, 62, 171-174. [CrossRef]

30. Nohál, L.; Hort, F.; Dvoracek, J.; Mazal, P. An experimental investigation of rolling contact fatigue of steels using acoustic emission method. Insight 2013, 55, 665-669. [CrossRef]

31. Kozochkin, M.P.; Kozochkin, M.P.; Porvatov, A.N. Estimation of Uncertainty in Solving Multi-Parameter Diagnostic Problems: Estimation of Uncertainty in Solving Multi-Parameter Diagnostic Problems. Meas. Tech. 2015, 58, 173-178. [CrossRef]

32. Calka, A.; Wexler, D. Mechanical milling assisted by electrical discharge. Nat. Cell Biol. 2002, 419, 147-151. [CrossRef]

33. Guo, Y.; Hou, P.; Shao, D.; Li, Z.; Wang, L.; Tang, L. High-Speed Wire Electrical Discharge Machining of Insulating Zirconia with a Novel Assisting Electrode. Mater. Manuf. Process. 2014, 29, 526-531. [CrossRef]

34. Volosova, M.A.; Okunkova, A.A.; Povolotskiy, D.E.; Podrabinnik, P.A. Study of electrical discharge machining for the parts of nuclear industry usage. Mech. Ind. 2015, 16, 706. [CrossRef]

35. Melnik, Y.A.; Kozochkin, M.P.; Porvatov, A.N.; Okunkova, A.A. On Adaptive Control for Electrical Discharge Machining Using Vibroacoustic Emission. Technologies 2018, 6, 96. [CrossRef]

36. Grigoriev, S.N.; Kozochkin, M.P.; Porvatov, A.N.; Volosova, M.A.; Okunkova, A.A. Electrical discharge machining of ceramic nanocomposites: Sublimation phenomena and adaptive control. Heliyon 2019, 5, e02629. [CrossRef] [PubMed]

37. Ay, M.; Etyemez, A. Optimization of the Effects of Wire EDM Parameters on Tolerances. Emerg. Mater. Res. 2020, 9, 527-531. [CrossRef]

38. Markopoulos, A.P.; Papazoglou, E.-L.; Karmiris-Obratański, P. Experimental Study on the Influence of Machining Conditions on the Quality of Electrical Discharge Machined Surfaces of aluminum alloy Al5052. Machines 2020, 8, 12. [CrossRef]

39. Grigoriev, S.N.; Teleshevskii, V.I. Measurement Problems in Technological Shaping Processes. Meas. Tech. 2011, 54, 744-749. [CrossRef]

40. Yarovchuk, A.V.; Maksimkin, O.P.; Tsay, K.V. Effect of Low-Cycle Thermocycling Treatment on Corrosion and Mechanical Properties of Corrosion-Resistant Steel 12Kh18N10T Irradiated with Neutrons. Met. Sci. Heat Treat. 2017, 59, 446-453. [CrossRef]

41. Zhelezkov, O.S.; Galiakhmetov, T.S.; Malakanov, S.A. Shaping the Hexahedral Head of a 12Kh18N10T Stainless Steel Bolt. Steel Transl. 2017, 47, 824-826. [CrossRef]

42. Gnedenkov, S.V.; Sinebryukhov, S.L.; Egorkin, V.S.; Vyaliy, I.E.; Imshinetskiy, I.M.; Kostina, M.V.; Muradyan, S.O.; Sergienko, V.I. Corrosion stability of austenitic steels 05Kh22AG15N8M2F and 12Kh18N10T in chloride-containing media. Prot. Met. Phys. Chem. Surf. 2017, 53, 910-915. [CrossRef]

43. Denisov, E.A.; Kompaniets, T.N.; Yukhimchuk, A.A.; Boitsov, I.E.; Malkov, I.L. Hydrogen and helium in nickel and 12Kh18N10T steel. Tech. Phys. 2013, 58, 779-786. [CrossRef]

44. Krymskiy, S.V.; Ilyasov, R.R.; Avtokratova, E.V.; Sitdikov, O.S.; Markushev, M.V. Intergranular Corrosion of Cryorolled and Aged D16 Aluminum Alloy. Prot. Met. Phys. Chem. Surf. 2017, 53, 1091-1099. [CrossRef]

45. Markushev, M.V.; Krymskiy, S.; Ilyasov, R.R.; Avtokratova, E.V.; Khazgalieva, A.A.; Sitdikov, O.S. Influence of Zr on intergranular corrosion of cast and cryorolled D16 aluminum alloy. Lett. Mater. 2017, 7, 447-451. [CrossRef]

46. Ponomarev, A.N. An Investigation of Diffusion in Droplets and of Evaporation of Volatile Components into Vacuum. High Temp. 2005, 43, 930-936. [CrossRef]

47. Nikitina, E.V.; Kazakovtseva, N.A. High Temperature Corrosion of 12Kh18N10T Steel in Molten Lithium and Potassium Chlorides with a Cerium Trichloride Addition. Russ. Met. 2018, 8, 747-749. [CrossRef]

48. Zakaryan, M.K.; Nazaretyan, K.T.; Aydinyan, S.V.; Kharatyan, S.L. NiO reduction by Mg plus C combined reducer at high heating rates. J. Therm. Anal. Calorim. 2020. [CrossRef]

49. Ming, F. Effects of low melting point oxides addition on sintering characteristics of ZnO-glass varistors. Rare Met. Mater. Eng. 2002, 31, 221-224.

50. Grigoriev, S.N.; Volosova, M.A.; Okunkova, A.A.; Fedorov, S.V.; Hamdy, K.; Podrabinnik, P.A.; Pivkin, P.M.; Kozochkin, M.P.; Porvatov, A.N. Electrical Discharge Machining of Oxide Nanocomposite: Nanomodification of Surface and Subsurface Layers. J. Manuf. Mater. Process. 2020, 4, 96. [CrossRef]

51. Grigoriev, S.N.; Volosova, M.A.; Okunkova, A.A.; Fedorov, S.V.; Hamdy, K.; Podrabinnik, P.A.; Pivkin, P.M.; Kozochkin, M.P.; Porvatov, A.N. Wire Tool Electrode Behavior and Wear under Discharge Pulses. Technologies 2020, 8, 49. [CrossRef]

52. Kubaschewski, O. Experimental thermochemistry of alloys. Thermochim. Acta 1988, 129, 11-27. [CrossRef]

53. Brzezińska, M.; García-Muñoz, P.; Ruppert, A.M.; Keller, N. Photoactive ZnO Materials for Solar Light-Induced CuxO-ZnO Catalyst Preparation. Materials 2018, 11, 2260. [CrossRef] [PubMed]

54. Lee, H.; Zhang, X.; Hwang, J.; Park, J. Morphological Influence of Solution-Processed Zinc Oxide Films on Electrical Characteristics of Thin-Film Transistors. Materials 2016, 9, 851. [CrossRef] [PubMed]

55. Zhikhareva, I.G.; Zhikharev, A.I. Modeling of Electrodeposited Precipitation Structure. Izv. Vuz. Khim. Kh. Tekh. 1993, 36, 52-58.

56. Hentrich, A.; Esquinazi, P.D. Effects of the Stacking Faults on the Electrical Resistance of Highly Ordered Graphite Bulk Samples. C 2020, 6, 49. [CrossRef]

57. Arbuzov, V.L.; Baldin, A.V.; Vuzynov, A.E.; Klotsman, S.M.; Matvienko, A.F.; Medvedev, G.V.; Pavlov, V.A. Third Stage Annealing Substructure of Electrical-Resistance of Gold, Silver, Copper Irradiated by Electron with Energy 5,5 meV. Fiz. Met. Metalloved. $1975,39,662-665$. 
58. Gelachov, M.V.; Khvostunkov, A.A.; Kiiko, V.M.; Mileiko, S.T. Graphite-Fiber Carbide-Matrix Composites 2. Structure and Electrical-Properties. Compos. Sci. Technol. 1994, 50, 179-186. [CrossRef]

59. Kuzin, V.V.; Grigor'Ev, S.N.; Volosova, M.A. Effect of a TiC Coating on the Stress-Strain State of a Plate of a High-Density Nitride Ceramic Under Nonsteady Thermoelastic Conditions. Refract. Ind. Ceram. 2014, 54, 376-380. [CrossRef]

60. Sobol, O.V.; Andreev, A.A.; Grigoriev, S.N.; Gorban, V.F.; Volosova, M.A.; Aleshin, S.V.; Stolbovoy, V.A. Physical characteristics, structure and stress state of vacuum-arc TiN coating, deposition on the substrate when applying high-voltage pulse during the deposition. Probl. Atomic Sci. Tech. 2011, 4, 174-177.

61. Volosova, M.A.; Grigor'Ev, S.N.; Kuzin, V.V. Effect of Titanium Nitride Coating on Stress Structural Inhomogeneity in OxideCarbide Ceramic. Part 4. Action of Heat Flow. Refract. Ind. Ceram. 2015, 56, 91-96. [CrossRef]

62. Grigoriev, S.N.; Sobol', O.; Beresnev, V.M.; Serdyuk, I.V.; Pogrebnyak, A.D.; Kolesnikov, D.A.; Nemchenko, U.S. Tribological characteristics of (TiZrHfVNbTa)N coatings applied using the vacuum arc deposition method. J. Frict. Wear 2014, 35, 359-364. [CrossRef]

63. Hasan, M.M.; Sharif, A.; Gafur, M.A. Effect of Minor Addition of Ni on the Microstructure and Properties of Zn-Based HighTemperature Solder. Effect of Minor Addition of Ni on the Microstructure and Properties of Zn-Based High-Temperature Solder. J. Electron. Mater. 2020, 49, 3990-4001. [CrossRef]

64. Zhikhareva, I.G. Calculation of Energy Characteristics of Nuclei Under Electrocrystallization Of Metals. Zh. Fiz. Khim. 1992, 66, 2232-2235.

65. Metel, A.S.; Stebulyanin, M.M.; Fedorov, S.V.; Okunkova, A.A. Power Density Distribution for Laser Additive Manufacturing (SLM): Potential, Fundamentals and Advanced Applications. Technologies 2018, 7, 5. [CrossRef]

66. Metel, A.S.; Bolbukov, V.P.; Volosova, M.; Grigoriev, S.N.; Melnik, Y. Equipment for deposition of thin metallic films bombarded by fast argon atoms. Instrum. Exp. Tech. 2014, 57, 345-351. [CrossRef]

67. Lazarenko, B.R.; Duradzhi, V.N.; Bryantsev, I.V. Effect of Incorporating an additional inductance on the characteristics of anode and cathode processes. Surf. Eng. Appl. Electrochem. 1979, 5, 8-13. 